Alma Mater Studiorum - Università di Bologna DEPARTMENT OF ECONOMICS

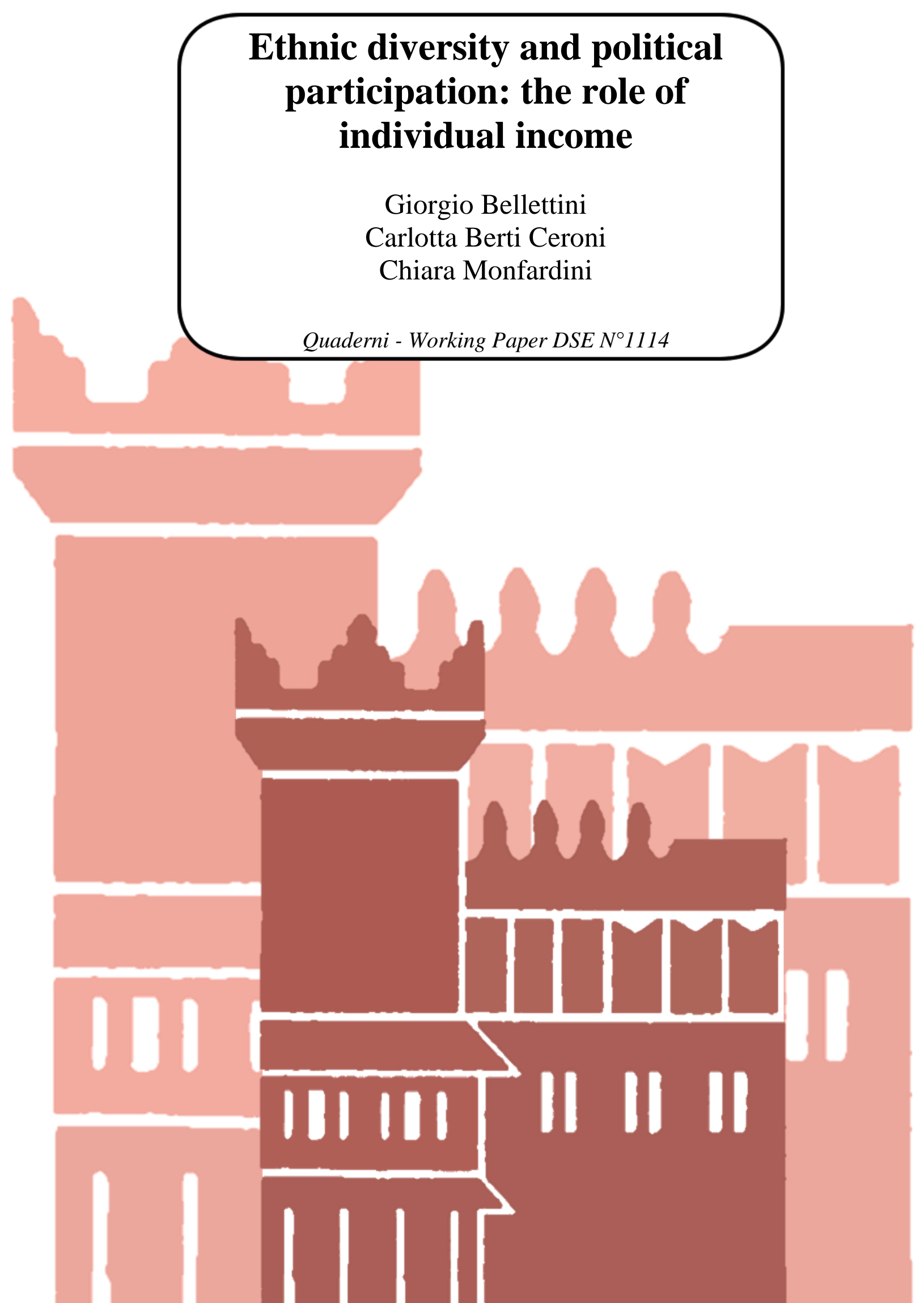




\title{
Ethnic diversity and political participation: the role of individual income
}

\author{
Giorgio Bellettini, Carlotta Berti Ceroni, Chiara Monfardini \\ Department of Economics, University of Bologna
}

November 22, 2017

\begin{abstract}
We exploit a unique dataset merging data on individual socio-economic characteristics and political participation in an Italian municipality to investigate the relationship between ethnic diversity in residential neighborhoods and individuals' propensity to vote. We document a sizable negative impact of diversity on overall electoral turnout which reflects differential effects at the individual level, depending on household equivalent income. Specifically, we show that ethnic heterogeneity in the neighborhood reduces the political participation of the poor, while it fosters that of the more affluent. These results highlight a potential democratic deficit stemming from reduced and unequal electoral turnout in increasingly ethnically heterogeneous neighborhoods.
\end{abstract}

Keywords: Ethnic heterogeneity, Electoral turnout, Income

JEL Classification Code: D720 Analysis of Collective Decision-Making : Political Processes : RentSeeking, Lobbying, Elections, Legislatures, and Voting Behavior 


\section{Introduction}

A recent and fast-growing empirical literature shows that contextual factors have complex effects on individuals' propensity to engage in civic and political activities. ${ }^{1}$ Among these factors, ethnic heterogeneity is arguably one of the most important and is likely to play a key role in the coming years as huge flows of migrants and refugees will dramatically increase the ethnic diversity of our societies.

As far as voting behavior and electoral participation is concerned, it has been extensively debated whether the recent decline in voting turnout in several democratic countries could be correlated to the increase in ethnic diversity brought about by international migration. Related to this, is it also plausible that these trends may cause an increase in political inequality, whereby the interests of some specific socio-economic groups (say the poor) tend to be under-represented in the political arena. This may be the case, for example, if ethnic diversity differently affects one's propensity to vote, depending on individual resources.

In order to address these questions we conduct an empirical investigation of the determinants of individual turnout based on a unique dataset on local elections in an Italian municipality, which merges information on socio-economic characteristics of about 370,000 individuals with electoral participation in two consecutive administrative elections in 2004 and 2009. In particular, we had access to information on individual turnout from official electoral lists and matched it with information on income and other individual characteristics, taken from official income tax files and registry office records. Different measures of contextual ethnic diversity were then constructed by aggregating individual information at the electoral precinct level, to capture possible effects on individual turnout of Italian (and EU) nationals following increasing exposure to ethnic others (non-EU nationals) in the neighborhood of residence, due to international immigration.

Our case of study is particularly suitable to investigate the effect of contextual ethnic diversity on individual electoral turnout, especially insofar as the former affects one's sense of belonging to and concern for the general community. First, starting from register data, we are able to measure diversity at the micro-level, in the precinct (neighborhood) of residence. Second, since in our context non-EU immigrants are not eligible to vote and eligible voters (Italian and EU nationals resident in the municipality) belong to an ethnically homogeneous group, we can rule out the possibility that the detected effect on

\footnotetext{
${ }^{1}$ See, for instance, Barber and Imai (2014), Bellettini and al. (2016), Bhatti et al. (2016), Dinesen and Sønderskovb (2015), Enos (2016), Fieldhouse and Cutts (2008).
} 
individual turnout is related to other factors such as, for instance, political competition among different ethnic groups. ${ }^{2}$

The availability of repeated information on individual turnout, income, and ethnic diversity across the 2004 and 2009 elections enables us to investigate and possibly identify heterogeneous effects of ethnic diversity which depend on personal income, controlling for other individual and contextual determinants of turnout, as well as for all unobserved time-invariant individual and contextual characteristics. The main result of our empirical analysis is that the effect of ethnic diversity on individuals' propensity to vote is different across income groups. In particular, we find that, for low income individuals, ethnic diversity in the neighborhood of residence reduces the probability of voting. This negative effect becomes weaker for individuals with higher income, turning to null moving up the income ladder and positive for upper income classes.

We can think of at least two arguments for why exposure to ethnic others can have a negative effect on the propensity to vote for the less affluent that may be offset by opposing forces as individual income increases, paving the way for increasing inequality in political participation as a consequence of immigration. First and foremost, the sense of alienation from the general community caused by increasing ethnic diversity in residential neighborhoods is likely to be stronger for the poor, who face or fear competition from immigrants in the labor market and in the access to social and public services. Instead, diversity may strengthen social concern and stimulate political participation among the rich, who have much less to fear from immigrants.

Second, ethnic diversity and immigration could generate ambivalent feelings and clashing interests in low-income voters which may depress their electoral turnout. ${ }^{3}$ For example,

\footnotetext{
${ }^{2}$ Immigrants may acquire the right to vote together with Italian or EU citizenship. However, as immigration is a relatively recent phenomenon and laws that regulate the acquisition of citizenship are quite restrictive in Italy, the number of Italian citizens of foreign origin (born from foreign parents, in Italy or abroad), though increasing, is still very small. According to ISTAT (2007), the estimated stock of foreigners who had acquired Italian citizenship as of 2006 was 215.000 , corresponding to $0,8 \%$ of the foreign population. Considering that the share of foreigners in Bologna was $1 \%$ of the nationwide total in 2006, the presumable number of naturalized immigrants in Bologna would be negligible compared to the size of the electorate. Moreover, although, in principle, non-EU immigrants may have acquired EU citizenship before moving to Bologna, the percentage of foreign eligible voters is actually very close to zero in our sample $(0.1 \%$ and $0.3 \%$ in 2005 and 2009 , respectively), implying even smaller shares of EU citizens of non-EU origin. Thus, we can safely posit that eligible voters are Italian and EU nationals of Italian and EU origin.

${ }^{3}$ Ambivalence has been found to have negative effects on political participation (see, for example, Mutz, 2002, and Johnson, 2014).
} 
the less affluent may refrain from voting for parties that support "pro-immigrant" policies (typically left-wing parties in our context) as they feel jeopardized by immigrants. At the same time, they may not want to support "anti-immigration" parties (typically right-wing parties in our context), which they reckon as not aligned with their interests along other dimensions. ${ }^{4}$ Instead, electoral participation may increase among the rich as a reaction to increased ethnic diversity, insofar as they do not necessarily face a clash of feelings between social concern for immigrants and fear of increased competition over employment opportunities or conflicting interests between "anti-immigrants" attitudes of right-wing parties and the conservative policies they support.

To our knowledge, this is the first study that documents differential effects of neighborhood ethnic diversity on the probability of voting depending on individual income. So far, this issue has been neglected in the literature, due to the limited availability of joint information on individual turnout, income and contextual characteristics of the neighborhood.

Although the focus of our paper is on ethnic diversity, our analysis also considers other potential determinants of electoral participation. Consistently with existing studies, we find that the most affluent, the eldest, the natives (born in the municipality), those who are married, and those who live in the city-center are more likely to vote. These characteristics are somehow related to the degree of integration and sense of belonging to one's community which may also be influenced by ethnic heterogeneity. As Blais (2000) puts it, "the socioeconomic profile of voters and abstainers provides support for a sociological interpretation of the act of voting as expressing one's sense of belonging to the larger community" (p. 52).

Overall, our results suggest that both individual and contextual socio-economic characteristics are important determinants of electoral participation and that increasing ethnic diversity of residential neighborhoods may be a driver of disaffection for politics among the less affluent while boosting participation among the rich, with overall negative effect on turnout. Insofar as reduced and unequal political participation translates into unequal political representation of the interests of different groups, these results point to a potential democratic deficit in increasingly diverse communities.

The remaining of the paper is organized as follows. Section 2 reviews the related

\footnotetext{
${ }^{4}$ Barone et al. (2016) propose an interpretation along these lines to explain their findings on aggregate turnout and votes obtained by different political coalitions in national elections in Italy. Specifically, they argue that "left-wing voters, who are ideologically in favor of a multi-ethnic society but are not happy about the immigration trends and regulations, might have decided not to vote instead of directly voting for the center-right coalition" (p.16).
} 
literature. Section 3 briefly describes the institutional framework while Section 4 provides data description. Section 5 illustrates the empirical strategy and shows the main results. Section 6 discusses sensitivity analysis, and Section 7 concludes.

\section{Related literature}

Several economists and political scientists have argued that increasing ethnic diversity tends to reduce trust and civic engagement (see, for instance, Alesina and La Ferrara, 2000, 2002, Putnam, 2007). Reduced social cohesion then translates into lower political participation and reduced propensity to vote.

According to this view, the mechanism underlying the relationship between heterogeneity and individual electoral turnout is the exposure to people of different ethnic background and social status, that affects one's sense of belonging to the community and therefore the propensity to vote. In order to capture such mechanism, it is important to measure contextual variables at the micro-level, i.e. in the neighborhood of residence of individuals, as measurement at the macro-level would be likely to capture other confounding effects. Dinesen and Sønderskovb (2015) forcefully make this point in the estimation of the relationship between social trust and ethnic diversity. Using Danish survey data linked with register-based data, they provide convincing evidence that ethnic diversity in the microcontext negatively affects social trust, whereas the effect vanishes when larger contextual units are considered.

The empirical literature about the relationship between ethnic (and racial) heterogeneity and individual turnout focuses on how the turnout of individuals who belong to a given ethnic or racial group is influenced by the share of individuals belonging to other groups who live in the same neighborhood. For example, in the case of Britain, Fieldhouse and Cutts (2008) use individual data from marked election registers to show that non-Asian turnout is negatively affected by the neighborhood density of Asian population (measured at census output or electoral ward level). For the US, Gimpel, Dyck and Shaw (2004) use individual registration and participation records for residents in 16 counties in Florida, Iowa, New Mexico and Pennsylvania matched with aggregate data at census tract or precinct level. They find that individual participation (especially for Republicans) is dampened in neighborhoods where the majority has different political affiliation and there is a high concentration of blacks and hispanics.

More recently, Barber and Imai (2014) show that increases in the out-group neighborhood proportion (measured at the census block level) depress the probability of turnout, 
where the out-group is defined in terms of race or political partisanship. An opposite result can be found in Enos (2016), who shows that out-group exposure enhances individuals' political participation, with white voters' turnout in Chicago dropping substantially after the relocation of African Americans over other neighborhoods. Bhatti et al. (2016) use data on local government elections in Denmark to study the association between exposure to ethnic others and turnout of voters of Danish origin. They find no influence of ethnic diversity on the propensity to vote, controlling for several individual characteristics and contextual variables, as well as for time invariant factors. In a recent meta-analysis of the determinants of voter turnout, Cancela and Geys (2016) report that the majority of studies looking at the impact of minority population shares on turnout detect a negative relationship.

Even if these contributions control for several individual characteristics and contextual effects, they typically do not include information on individual income. Therefore, they cannot investigate the heterogeneous effect of ethnic diversity depending on individual resources. Our empirical analysis provides a first contribution in this direction and addresses the issue of whether immigration can have indirect negative effects on the quality of democracy by reducing overall turnout and equality in political participation. ${ }^{5}$

Furthermore, none of the above cited papers aim at capturing the purely contextual effect of interethnic exposure on the probability of voting, which is instead the focus of our analysis. Rather, they focus on the relationship between diversity and participation based either on political competition (according to which, for example, the rich might be induced to participate more in order to counterbalance the increased number of poor, immigrants voters), or on within-group mobilization of individuals who belong to different ethnic and racial groups, and are all entitled to vote. As already mentioned, such mechanisms are not at work in our context, because we consider how Italians and Eu citizens' propensity to vote is affected by the proximity with non-EU immigrants, who are not entitled to vote.

Before concluding this section, we should mention the few other individual turnout studies based on register data. Bhatti et al. (2012) investigate the impact of age on individual political participation in Denmark, Finland and Lubbock, Texas. They limit their attention to age and do not consider any other determinant of turnout. Martikainen et al (2005) use data from Finnish parliamentary elections to estimate the effect of individual socioeconomic factors, including personal taxable income, but ignore any contextual

\footnotetext{
${ }^{5}$ One exception is Bhatti et al. (2016) who rely on data from administrative source including information on individual income. However, they do not investigate the possibility of non linear effects of ethnic exposure on turnout depending on individual income.
} 
determinant of turnout.

\section{The institutional framework}

We focus on two consecutive municipal elections held in June 2004 and 2009 in Bologna, a large municipality of about 370,000 inhabitants located in the Center-North of Italy.

According to the Italian Law, the mayor and the municipality council are appointed through local elections which take place every five years. The mayor is elected directly and faces a two-term limit. Each candidate must be supported by a list or a coalition of lists of residents in the municipality, Italian or EU citizens, who run for a seat in the council. In municipalities with more than 15.000 inhabitants, such as Bologna, the mayor is elected through a two-round majority system: if none of the candidates reaches the absolute majority of valid votes in the first round, the two most voted candidates enter in a runoff election ("ballottaggio") and the one who gets the relative majority is appointed.

In the case of Bologna, Sergio Cofferati, a former union leader, was appointed after the first round of the 2004 elections, when the turnout rate was $81.81 \%$. In 2009, Cofferati chose not to run for re-election and the elected mayor was Flavio Delbono, a former professor of Economics at the University of Bologna, who won the elections in the second round. In the first and second round, the turnout rate was $76.39 \%$ and $62.20 \%$, respectively.

The municipal electoral register in Bologna entails 436 precincts which include geographically close areas. Eligible voters (Italian and EU citizens above 18 years of age who are residents in the municipality) are registered in a precinct depending on their residence address. Registration is automatic for Italian citizens. Instead, eligible foreign residents must apply for registration on electoral lists in order to vote. ${ }^{6}$

\section{Data description}

Our data come from the Municipal Statistical Office in Bologna. A crucial advantage with respect to most existing studies is represented by the joint availability of repeated administrative individual-level data on the three key variables of our analysis, namely turnout, income and ethnicity, which is indeed quite unique in studies of the determinants of individual turnout. ${ }^{7}$ We merge different official registers into an individual-level panel dataset

\footnotetext{
${ }^{6}$ For more detailed information on the institutional and electoral framework see Bellettini et al. (2016).

${ }^{7}$ To our knowledge, the only other paper that relies on a longitudinal data set from administrative source with repeated information on turnout, individual characteristics (including income), and neighborhood characteristics is Bhatti et al. (2016).
} 
which allows us to identify the causal effect of ethnicity, income, and their interaction on turnout, net of possible confounding factors.

We observe individual turnout for all eligible voters in the 2004 and 2009 administrative elections from official election register data. ${ }^{8}$ Using official data, we avoid the well-known problems related to over-reporting and under-representation of citizens with lower propensity to vote, which plague most turnout analyses, that are typically based on survey data.

We had access to income tax files in the two election years. Availability of information on official individual post-tax income is truly unique in turnout studies. Moreover, matching these income data with election register data and civil register data, we are able to attach, to each eligible voter, the income earned by all his/her family members, and to compute his/her equivalent family income. ${ }^{9}$ We are not aware of any other paper using official income data to construct a measure of family income, although it is arguably a relevant variable which shapes individual political participation.

Using civil register data which collect information on individual citizenship for the whole resident population, we link different measures of contextual ethnic diversity at the electoral precinct level to each eligible voter. This can be considered as a good approximation of the individual's residential neighborhood because it includes geographically contiguous areas. ${ }^{10}$

As eligible voters (Italian and EU citizens) belong to a homogeneous ethnic group while non voting immigrants (non-EU citizens) can be considered ethnic others (that is, culturally and/or somatically different), the use of immigrants' concentration as a measure of interethnic exposure seems the most natural choice in our context. Thus, we operationalize ethnic diversity faced by eligible voters in the neighborhood of residence by the share of non-EU foreigners living in the precinct over the total precinct population. ${ }^{11}$ Following Bellettini et al. (2016), we restrict the definition of ethnic others to non-EU foreigners from Africa and Asia, who are likely to be perceived by eligible voters as more ethnically distant than non voting immigrants from non-EU East European countries (the other largest foreigners' group), and calculate ethnic diversity using the share of African

\footnotetext{
${ }^{8}$ For the 2009 election we considered only the first-round vote.

${ }^{9}$ Civil registers information was drawn at the available calendar time closest to the election date.

${ }^{10}$ The municipal electoral register in Bologna entails 436 precincts, with average number of residents per precinct around 860 in both years and average geographical extension of about 0.32 square kilometers.

${ }^{11}$ In the sensitivity analysis, we will present estimates obtained using an Herfindal index of ethnic fragmentation as an alternative measure of ethnic diversity.
} 
and Asian over the total precinct population. ${ }^{12}$

The matching with civil register data provides us with a large set of control variables at the individual and the precinct level. Table A1 in the Appendix describes the variables on which we build our econometric analysis. Our initial dataset consists of all individuals (both eligible voters and residents with no right to vote) residing in the municipality of Bologna in 2004 and 2009, i.e. about 378,000 observations per year. In order to select our estimation sample we proceeded in three steps. First, we performed a careful cleaning of all cases with missing information or anomalies on relevant variables, as well as all cases showing discrepancies emerged by a number of cross-checks. We also dropped all individuals residing in communities for educational, religious, therapeutic and military reasons. The resulting dataset contains 364,187 observations in 2004 and 364,110 in 2009. We checked that the sample selection has a very negligible impact on the distribution of all variables of interest for our econometric analysis. Second, we used this dataset to compute precinct-level measures of ethnic diversity - the percentage of immigrants (all and coming from Africa and Asia), and other contextual variables, such as mean income, the Gini index (both based on equivalent net income), population density, and the percentage of homeowners. Finally, we selected only the eligible voters: 302,588 individuals in 2004 and 284,434 in 2009 (corresponding to $83 \%$ and $78 \%$ of the previous sample respectively).

In Table A2 we present the main summary statistics on the two pooled years, for the whole sample of eligible voters and for a balanced panel sub-sample, that includes only the eligible voters who are observed in both years. The latter observations are the ones that will contribute to our estimation exercises. It can be noticed that the discrepancies between the whole sample and the balanced-panel one are limited to age and age-dependent variables such as marriage status and years of residence in Bologna. This is explained by the fact that the latter sample includes only individual who were already 18 years old and entitled to vote in the 2004 election.

\footnotetext{
${ }^{12}$ Note that we did not consider immigrants from other continents since their number is very small.
} 


\section{$5 \quad$ Estimation strategy and results}

In order to identify the heterogeneous impact of ethnic diversity on turnout we exploit the observation of individual incomes on a continuous basis and for a large sample to categorize it into ten classes, based on corresponding quantiles, and specify a linear probability model, which entails a very flexible pattern for the partial effects of interest:

$$
\text { turnout }_{i c t}=\beta_{1}+\beta_{2} h_{e t}+\sum_{j=2}^{10} \beta_{3 j} i n c_{-} j_{i t}+\sum_{j=2}^{10} \beta_{4 j} h e t_{c t} * i n c_{-} j_{i t}+\beta_{5} X_{i c t}+\eta_{t}+a_{i}+u_{c}+\varepsilon_{i c t}
$$

where $i$ denotes the eligible voter, $c$ denotes the context/neighborhood in which she resides (i.e. the electoral precinct), and $t=2004,2009$. The binary dependent variable turnout $_{i c t}$ indicates individual participation at elections, het $_{c t}$ is the ethnic heterogeneity measure, $i n c_{-} j, j=2, \ldots, 10$, is a set of dummies denoting the income class, $X_{i c t}$ is a vector of observed individual and contextual time variant controls, $\eta_{t}$ is the election year effect, $a_{i}$ is the fixed effect which captures all unobserved individual time invariant characteristics, while $u_{c}$ represents unobserved time invariant contextual variables. The idiosyncratic error term is assumed to be uncorrelated with all the other right-hand side variables, observed and unobserved. Table A1 in the Appendix presents the distribution of income classes and other variables such as age and number of family components that we transform into categorical ones in order to achieve a flexible functional form.

It is well known that model (1) implies a linear form of the response probability:

$$
p_{i c t}=\operatorname{prob}\left(\text { turnout }_{i c t}=1 \mid W_{i c t}\right)=W_{i c t} \delta
$$

where all parameters are collapsed in $\delta$ and all the right-hand side variables but the error $\varepsilon_{i c t}$ are collected in $W_{i c t}$. The interaction term between ethnic heterogeneity and income classes dummies makes it possible to analyze whether and along which pattern the partial

effect of ethnic diversity changes for different income classes. The partial effects of ethnic heterogeneity in model (1) are the set of values:

$$
\frac{\partial p_{i c t}}{\partial h e t_{c t}}=\beta_{2}+\beta_{4 j} i n c_{-} j_{i t}, \quad \quad j=2, \ldots, 10
$$

and measure the change in the turnout probability for an individual in income class $j$ caused by a 1 percentage point increase in the concentration of foreign residents in the precinct where she resides. The partial effect of ethnic heterogeneity for individuals in the lowest income class is given by $\beta_{2}$. 
We start estimating (1) by pooled OLS. Later, we will exploit the panel structure of the data and rely on individual fixed effects and individual and contextual fixed effects models. These models allow us to purge out the bias due to unobserved time individual individual and contextual characteristics from the OLS estimates, a possibility which is quite unique in individual turnout studies.

\subsection{Pooled OLS regressions}

The OLS estimation approach collapses all the unobserved components of model (1) in a composite error term $\eta_{i c t}=a_{i}+u_{c}+\varepsilon_{i c t}$. As a consequence, this section's results are based on the assumption that both $a_{i}$ and $u_{c}$ are uncorrelated with the included regressors. In other words, all possible omitted variable bias is accounted for by the (large number of) controls that we observe at the individual and contextual level.

Table 1 displays the results obtained on the coefficients of interest estimating eq. (1) by OLS using as ethnic diversity measures: (i) the share of non-voting foreign residents of all nationalities (left panel, columns 2-4), (ii) the share of non-voting foreigners from Asia and Africa (right panel, columns 5-7). Both sets of results are displayed for specifications including an increasing set of controls (no controls, individual controls, contextual controls).

Given the rich information contained in our dataset we can account for several determinants of individual turnout which have been identified in the empirical literature, and capture both individual and contextual characteristics. ${ }^{13}$ The latter, which we measure at the precinct level, include mean income, population density, the percentage of homeowners and the Gini index. As for individual level controls, we observe age, number of household components, marital status, gender, residence in the city center, residential mobility (having moved to Bologna from other municipalities, years of residence in Bologna), being born in Bologna, being a foreign (EU citizen) eligible voter. ${ }^{14}$

\footnotetext{
${ }^{13}$ For a review of the relevant empirical literature, see Smets and Van Ham (2013).

${ }^{14} \mathrm{~A}$ potential flaw of our dataset is the lack of information about voters' education, which may be a source of omitted variable bias for the OLS estimator considered here. In the fixed effects analysis, that we will develop in the following Section, we will be able to test whether unobserved education biases our estimates by relying on the sub-sample of voters aged 25 years or more in 2004, for whom we can assume that the educational level is unchanged across the two observed years.
} 
Table 1. Turnout linear probability models. Pooled OLS results

\begin{tabular}{|c|c|c|c|c|c|c|}
\hline \multirow[b]{2}{*}{ year 2009} & \multicolumn{3}{|c|}{ All non voting foreigners } & \multicolumn{3}{|c|}{ Foreigners from Asia and Africa } \\
\hline & $\begin{array}{l}-0.0574^{* * *} \\
(0.0013)\end{array}$ & $\begin{array}{r}-0.0521^{* * *} \\
(0.0012)\end{array}$ & $\begin{array}{r}-0.0551^{* * *} \\
(0.0013)\end{array}$ & $\begin{array}{r}-0.0646^{* * *} \\
(0.0011)\end{array}$ & $\begin{array}{c}-0.0574^{* * *} \\
(0.0011)\end{array}$ & $\begin{array}{c}-0.0554^{* * *} \\
(0.0011)\end{array}$ \\
\hline percentage of foreigners & $\begin{array}{l}-0.0059^{* * *} \\
(0.0005)\end{array}$ & $\begin{array}{r}-0.0059^{* * *} \\
(0.0005)\end{array}$ & $\begin{array}{r}-0.0044^{* * *} \\
(0.0005)\end{array}$ & $\begin{array}{r}-0.0059^{* * *} \\
(0.0007)\end{array}$ & $\begin{array}{c}-0.0057^{* * *} \\
(0.0007)\end{array}$ & $\begin{array}{c}-0.0041^{* * *} \\
(0.0007)\end{array}$ \\
\hline 2.inc net equiv* perc foreign & $\begin{array}{l}0.0008 \\
(0.0006)\end{array}$ & $\begin{array}{r}0.0018^{* * *} \\
(0.0006)\end{array}$ & $\begin{array}{r}0.0018^{* * *} \\
(0.0006)\end{array}$ & $\begin{array}{r}-0.0002 \\
(0.0009)\end{array}$ & $\begin{array}{c}0.0006 \\
(0.0009)\end{array}$ & $\begin{array}{c}0.0005 \\
(0.0009)\end{array}$ \\
\hline 3.inc net equiv*perc foreign & $\begin{array}{l}0.0019^{* * *} \\
(0.0006)\end{array}$ & $\begin{array}{r}0.0031^{* * *} \\
(0.0006)\end{array}$ & $\begin{array}{r}0.0031^{* * *} \\
(0.0006)\end{array}$ & $\begin{array}{r}0.0014 \\
(0.0009)\end{array}$ & $\begin{array}{c}0.0021^{* *} \\
(0.0009)\end{array}$ & $\begin{array}{c}0.0021^{* *} \\
(0.0009)\end{array}$ \\
\hline 4.inc net equiv*perc foreign & $\begin{array}{l}0.0035^{* * *} \\
(0.0006)\end{array}$ & $\begin{array}{r}0.0044^{* * *} \\
(0.0006)\end{array}$ & $\begin{array}{r}0.0044^{* * *} \\
(0.0006)\end{array}$ & $\begin{array}{r}0.0033^{* * *} \\
(0.0009)\end{array}$ & $\begin{array}{c}0.0039^{* * *} \\
(0.0009)\end{array}$ & $\begin{array}{c}0.0040^{* * *} \\
(0.0009)\end{array}$ \\
\hline 5.inc net equiv*perc foreign & $\begin{array}{l}0.0035^{* * *} \\
(0.0006)\end{array}$ & $\begin{array}{r}0.0041^{* * *} \\
(0.0006)\end{array}$ & $\begin{array}{r}0.0042^{* * *} \\
(0.0006)\end{array}$ & $\begin{array}{r}0.0028^{* * *} \\
(0.0009)\end{array}$ & $\begin{array}{c}0.0033^{* * *} \\
(0.0009)\end{array}$ & $\begin{array}{c}0.0033^{* * *} \\
(0.0009)\end{array}$ \\
\hline 6.inc net equiv*perc foreign & $\begin{array}{l}0.0044^{* * *} \\
(0.0006)\end{array}$ & $\begin{array}{r}0.0049^{* * *} \\
(0.0006)\end{array}$ & $\begin{array}{r}0.0049^{* * *} \\
(0.0006)\end{array}$ & $\begin{array}{r}0.0041^{* * *} \\
(0.0009)\end{array}$ & $\begin{array}{c}0.0046^{* * *} \\
(0.0009)\end{array}$ & $\begin{array}{c}0.0047^{* * *} \\
(0.0009)\end{array}$ \\
\hline 7.inc net equiv*perc foreign & $\begin{array}{l}0.0046^{* * *} \\
(0.0006)\end{array}$ & $\begin{array}{r}0.0050^{* * *} \\
(0.0006)\end{array}$ & $\begin{array}{r}0.0051^{* * *} \\
(0.0006)\end{array}$ & $\begin{array}{r}0.0044^{* * *} \\
(0.0009)\end{array}$ & $\begin{array}{c}0.0048^{* * *} \\
(0.0009)\end{array}$ & $\begin{array}{c}0.0049^{* * *} \\
(0.0008)\end{array}$ \\
\hline 8.inc net equiv*perc foreign & $\begin{array}{l}0.0058^{* * *} \\
(0.0006)\end{array}$ & $\begin{array}{r}0.0060^{* * *} \\
(0.0006)\end{array}$ & $\begin{array}{r}0.0062^{* * *} \\
(0.0006)\end{array}$ & $\begin{array}{r}0.0060^{* * *} \\
(0.0009)\end{array}$ & $\begin{array}{c}0.0061^{* * *} \\
(0.0008)\end{array}$ & $\begin{array}{c}0.0064^{* * *} \\
(0.0008)\end{array}$ \\
\hline 9.inc net equiv* perc foreign & $\begin{array}{l}0.0060^{* * *} \\
(0.0006)\end{array}$ & $\begin{array}{r}0.0059^{* * *} \\
(0.0006)\end{array}$ & $\begin{array}{r}0.0062^{* * *} \\
(0.0006)\end{array}$ & $\begin{array}{r}0.0059^{* * *} \\
(0.0009)\end{array}$ & $\begin{array}{c}0.0057^{* * *} \\
(0.0009)\end{array}$ & $\begin{array}{c}0.0062^{* * *} \\
(0.0009)\end{array}$ \\
\hline 10.inc net equiv*perc foreign & $\begin{array}{l}0.0059^{* * *} \\
(0.0006)\end{array}$ & $\begin{array}{r}0.0058^{* * *} \\
(0.0006)\end{array}$ & $\begin{array}{r}0.0062^{* * *} \\
(0.0006)\end{array}$ & $\begin{array}{r}0.0056^{* * *} \\
(0.0009)\end{array}$ & $\begin{array}{c}0.0054^{* * *} \\
(0.0009)\end{array}$ & $\begin{array}{c}0.0060^{* * *} \\
(0.0009)\end{array}$ \\
\hline Non-interacted income classes & YES & YES & YES & YES & YES & YES \\
\hline Individual controls & NO & YES & YES & NO & YES & YES \\
\hline Contextual controls & NO & NO & YES & $\mathrm{NO}$ & NO & YES \\
\hline Constant & $\begin{array}{l}0.7736^{* * *} \\
(0.0046)\end{array}$ & $\begin{array}{r}0.7858^{* * *} \\
(0.0053)\end{array}$ & $\begin{array}{r}0.7274^{* * *} \\
(0.0075)\end{array}$ & $\begin{array}{r}0.7578^{* * *} \\
(0.0042)\end{array}$ & $\begin{array}{c}0.7689^{* * *} \\
(0.0050)\end{array}$ & $\begin{array}{c}0.7120^{* * *} \\
(0.0073)\end{array}$ \\
\hline $\begin{array}{l}\text { R-squared } \\
\text { Number of observations }\end{array}$ & $\begin{array}{l}0.0381 \\
483,182\end{array}$ & 0.0809 & 0.0816 & 0.0377 & 0.0806 & 0.0814 \\
\hline
\end{tabular}

Robust S.E. in brackets

${ }^{*} \mathrm{p}<0.10,{ }^{* *} \mathrm{p}<0.05, * * * \mathrm{p}<0.01$

Individual controls: age classes, ncomp classes, female married, city center residence, foreign citizen

moved, moved*years of residence, non native.

Contextual controls: precinct mean inc equiv, gini inc net equiv, pop density, perc. homeown.

The coefficients of the share of all foreigners and its interaction terms with income classes are found to be affected, despite not dramatically, by the insertion of observable individual and contextual characteristics. The baseline coefficient, which corresponds to the first income class ranges from -0.006 (first column) to -0.004 (third column). Interest- 
ingly, when the same specifications are estimated using the share of immigrants from Asia and Africa, the value of the baseline and interaction coefficients are almost unaffected, with the former ranging between the same values (see the fourth and the sixth column). The standard errors reported in Table 1 are heteroskedasticity robust. Since in our sample eligible voters can be clustered both at the precinct level and at the household level, we checked that the significance of our coefficient of interest is preserved when we evaluate clustered standard errors at either level.

The substantial similarity of the results obtained with the two alternative measures of ethnic diversity suggests that the effect is driven by the neighborhood concentration of immigrants from Asian and African countries, that is by ethnicities who are culturally and somatically more distant from Europeans and therefore more likely to be perceived as ethnic others by eligible voters. ${ }^{15}$

Table 2 reports the partial effects of the percentage of African and Asian residents over the income distribution, using the estimation results of the model with the largest set of observable controls (last column of Table 1).

\footnotetext{
${ }^{15}$ Note that a similar pattern was found by Bellettini et al. (2016) in a precinct-level analysis of the impact of ethnic diversity on aggregate turnout. Here, we are able to uncover the individual-level mechanism underlying the previous aggregate results, and show that it is precisely the exposure to the narrower measure of diversity that affects the individual's political participation.
} 
Table 2. Partial effects of percentage of foreigners from Asia and Africa by income class

\begin{tabular}{ccccccc}
\hline \hline \multicolumn{7}{c}{ Linear probability model - Pooled OLS -all controls } \\
\hline Income class & $\mathrm{dy} / \mathrm{dx}$ & $\begin{array}{c}\text { Std. Err. } \\
\text { Delta-method }\end{array}$ & $\mathrm{z}$ & $\mathrm{P}>\mathrm{z}$ & {$[95 \%$ Conf.Interval $]$} \\
1 & -0.0041 & 0.0007 & -5.5700 & 0.0000 & -0.0055 & -0.0026 \\
2 & -0.0035 & 0.0006 & -5.9700 & 0.0000 & -0.0047 & -0.0024 \\
3 & -0.0019 & 0.0005 & -3.5900 & 0.0000 & -0.0030 & -0.0009 \\
4 & -0.0001 & 0.0005 & -0.1900 & 0.8520 & -0.0011 & 0.0009 \\
5 & -0.0008 & 0.0005 & -1.5100 & 0.1310 & -0.0018 & 0.0002 \\
6 & 0.0006 & 0.0005 & 1.2200 & 0.2210 & -0.0004 & 0.0016 \\
7 & 0.0008 & 0.0005 & 1.7600 & 0.0780 & -0.0001 & 0.0018 \\
8 & 0.0023 & 0.0004 & 5.1800 & 0.0000 & 0.0014 & 0.0032 \\
9 & 0.0021 & 0.0005 & 4.3700 & 0.0000 & 0.0012 & 0.0031 \\
10 & 0.0019 & 0.0005 & 3.5700 & 0.0000 & 0.0009 & 0.0029 \\
\hline
\end{tabular}

Number of observations: 483,182

Individual controls: age classes, ncomp classes, city center residence, income classes

Contextual controls: precinct mean inc equiv, gini inc net equiv, pop density, perc homeown.

Our main finding is the strongly heterogeneous effect of ethnic diversity on individual turnout for different levels of individual income. According to our estimates, the probability of turnout of lower income individuals decreases in the presence of higher concentration of immigrants, but this negative effect becomes weaker as income increases, turning to null in the middle part of the distribution and positive in the top part. In other words, diversity seems to have a marginalization effect on the less affluent (i.e. people whose equivalent income is in the bottom three classes, that is below 13,380 euros per year) and a mobilization effect on the more affluent (i.e. people whose equivalent income is in the upper four classes, that is above 20,820 euros per year). The effect is not statistically different from zero for the middle class. Figure 1 allows for a visual inspection of this pattern. 


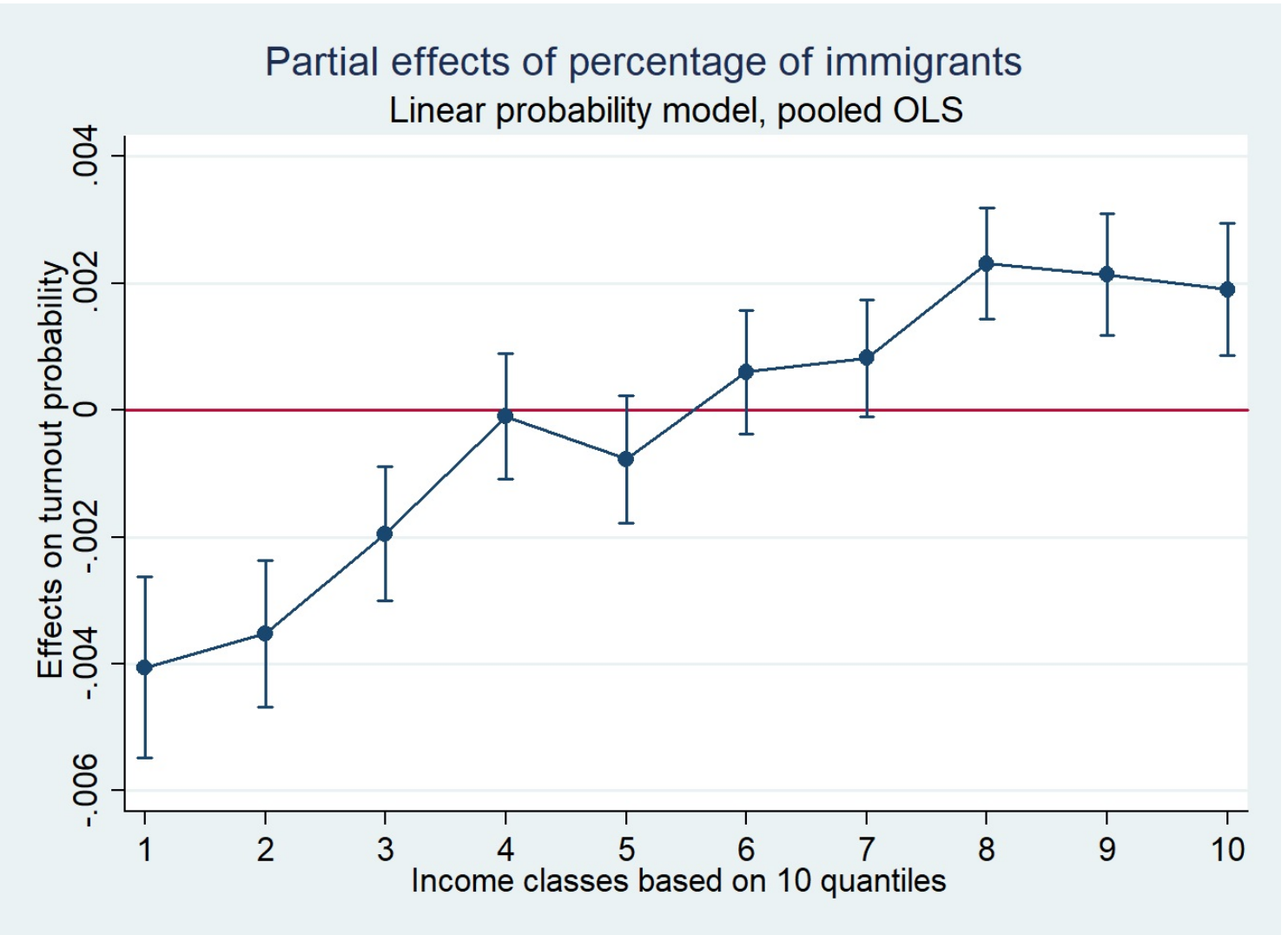

Figure 1

In Table 3 we show the results of a parallel model which does not include any interaction term and therefore does not allow to uncover the pattern of the varying impact of exposure to neighborhood heterogeneity. Adopting this model, we would be tempted to conclude that a 1 percentage point increase in the share of immigrants implies a decrease of 0.04 percentage points (p.p.) in the propensity to vote of any eligible voter, regardless of her income. Though significant, the size of the coefficient is very small and one may wrongly conclude that exposure to ethnic others is only marginally relevant for the propensity to vote. Instead, our results show that its effect is definitely more sizable and with opposite signs for individuals at the bottom and at the top of the income ladder, ranging from 0,4 p.p. to $+0,2$ p.p.. 
Table 3 Turnout linear probability models. Pooled OLS results.

\begin{tabular}{lc}
\hline \multicolumn{2}{c}{ Ethnic diversity: immigrants from Asia and Africa. No interaction with income classes. } \\
\hline & POOLED \\
year 2009 & $-0.0555^{* * *}$ \\
& $(0.0011)$ \\
perc foreign asia africa & $-0.0004^{* *}$ \\
Non-interacted income classes & $(0.0002)$ \\
Individual controls & YES \\
Contextual controls & YES \\
Constant & YES \\
& $0.6938^{* * *}$ \\
R-squared: 0.0811 & $(0.0066)$ \\
Number of observations: 483,182 & \\
\hline
\end{tabular}

Robust S.E. in brackets

${ }^{*} \mathrm{p}<0.10,{ }^{* *} \mathrm{p}<0.05,{ }^{* * *} \mathrm{p}<0.01$

Individual controls: age classes, ncomp classes, female, married, city center residence,

foreign citizien, moved, moved*years of residence, non native. income classes

Contextual controls: precinct mean inc equiv, gini inc net equiv, pop density, perc homeown.

Our findings for individual and contextual controls, other than individual income and ethnic diversity, are in line with the "sociological interpretation of the act of voting" (Blais, cit.), in which the propensity to vote is positively related to social awareness and the strength of community ties, as well as to individual resources. In particular, consistently with previous results in the literature, we find that individual turnout increases with age, although it declines for the elderly (above 75 years of age in our sample), and is higher for men, the married, residents in the city-center, and natives (born in Bologna). Instead, the probability of voting is lower for recent movers and foreigners. We also find that individuals who belong to households with four components (for example, married with two children) are more likely to vote than singles and those who live with one or two others. The propensity to vote declines for individuals who belong to large households (five components or more). ${ }^{16}$

These results may reflect increasing awareness of social and civic matters, related to

\footnotetext{
${ }^{16}$ Table A6 in the Appendix reports the full set of estimation results using the percentage of immigrants from Africa and Asia.
} 
parenthood and interactions within the household, tempered by reduced time for political discussion and participation as the household gets very large. Among contextual variables, the Gini index is found to have a negative and significant coefficient, holding precinct average income constant, which suggests a negative effect of income inequality in the neighborhood of residence on electoral turnout. As discussed in Bellettini et al. (2016), income inequality is another dimension of neighborhood heterogeneity, together with ethnic diversity, that may influence one's sense of belonging to the community, pro-social behavior and political participation. Other contextual variables, such as the percentage of homeowners and population density, have positive, but rather small effect in our context, possibly because we are already controlling for individual characteristics which are related to residential stability (natives, movers, years of residence) and the strength of social interactions (e.g. center city residence).

\section{$5.2 \quad$ Fixed effect models}

To improve the inference obtained so far, in this Section we exploit the repeated observation of voters in our data and estimate eq. (1) by means of fixed effects specifications to control for time invariant unobserved individual and contextual factors. The former may encompass personal and socialization traits of the eligible voter, while the latter may reflect social and cultural characteristics that are peculiar to the precinct. All these may be correlated with the observed individual and contextual observed factors and represent a source of omitted variable bias.

The use of two waves of data raises the issue of those voters who change their precinct of residence between the two elections, and for whom the contextual unobserved effect $u_{c}$ cannot be assumed to be time invariant. Aware of this, we start by keeping all voters in the sample and adopt an Individual Fixed Effects (IFE) approach where $u_{c}$ is absorbed in the error term, that is $\eta_{i c t}^{I F E}=u_{c}+\varepsilon_{i c t} .{ }^{17}$ Consistency of the IFE estimator requires that the unobserved contextual effect $u_{c}$ is uncorrelated with the observed individual and contextual regressors, an assumption which is the more plausible the larger the number of observed individual and contextual controls. In this case, for eligible voters moving from precinct $c$ to precinct $c^{\prime}$ between the two years, the difference $u_{c}-u_{c^{\prime}}$ will be uncorrelated

\footnotetext{
${ }^{17}$ The Fixed Effects identification strategy exploits time variation in turnout and in the main regressors of interest. In our sample, this reduces the number of observations to about 40000 individuals. We carefully checked that this IFE subsample does not systematically differ from the balanced-panel sample described in the previous section. Moreover, we evaluate the observed proportion of within variation on overall variation and find it to be sizeable for most regressors (see Table A4).
} 
with the time difference in the observed individual and contextual regressors.

Next, in order to keep the unobserved contextual factors constant over time, we restrict the sample to eligible voters that did not change precinct of residence between 2004 and 2009 (non movers) and turn to an Individual and Contextual Fixed Effects (ICFE) approach, where the unobserved contextual heterogeneity $u_{c}$ is explicitly controlled for and therefore removed from the error term, that is $\eta_{i c t}^{I C F E}=\varepsilon_{i c t}$.

Table 4 and Figure 2 report the partial effects obtained with the IFE specification, using the concentration of immigrants from Asian and African countries as ethnic diversity measure and including all the observed time-varying individual and contextual controls. As in the pooled OLS estimation, the negative partial effect of ethnic diversity on turnout observed for individuals in the bottom class diminishes moving up the income ladder and becomes positive for individuals in the upper four classes.

Table 4. Partial effects of percentage of foreigners from Asia and Africa by income class

\begin{tabular}{ccccccc}
\hline \multicolumn{7}{c}{ Linear probability model - Individual Fixed Effects } \\
\hline Income class & $\mathrm{dy} / \mathrm{dx}$ & $\begin{array}{c}\text { Std. Err. } \\
\text { Delta-method }\end{array}$ & $\mathrm{z}$ & $\mathrm{P}>\mathrm{z}$ & \multicolumn{2}{l}{$[95 \%$ Conf.Interval $]$} \\
\hline 1 & -0.0041 & 0.0010 & -4.2800 & 0.0000 & -0.0060 & -0.0022 \\
2 & -0.0046 & 0.0008 & -6.1000 & 0.0000 & -0.0061 & -0.0031 \\
3 & -0.0041 & 0.0007 & -5.7000 & 0.0000 & -0.0056 & -0.0027 \\
4 & -0.0023 & 0.0007 & -3.3900 & 0.0010 & -0.0037 & -0.0010 \\
5 & -0.0001 & 0.0007 & -0.2100 & 0.8340 & -0.0015 & 0.0012 \\
6 & -0.0002 & 0.0007 & -0.2800 & 0.7760 & -0.0015 & 0.0011 \\
7 & 0.0007 & 0.0006 & 1.0800 & 0.2810 & -0.0006 & 0.0019 \\
8 & 0.0026 & 0.0007 & 3.9000 & 0.0000 & 0.0013 & 0.0038 \\
9 & 0.0031 & 0.0007 & 4.5400 & 0.0000 & 0.0018 & 0.0045 \\
10 & 0.0039 & 0.0008 & 4.6700 & 0.0000 & 0.0023 & 0.0056 \\
\hline
\end{tabular}

Number of individuals: 241,591

Individual controls: age classes, ncomp classes, city center residence, income classes

Contextual controls: precinct mean inc equiv, gini inc net equiv, pop density, perc homeown. 


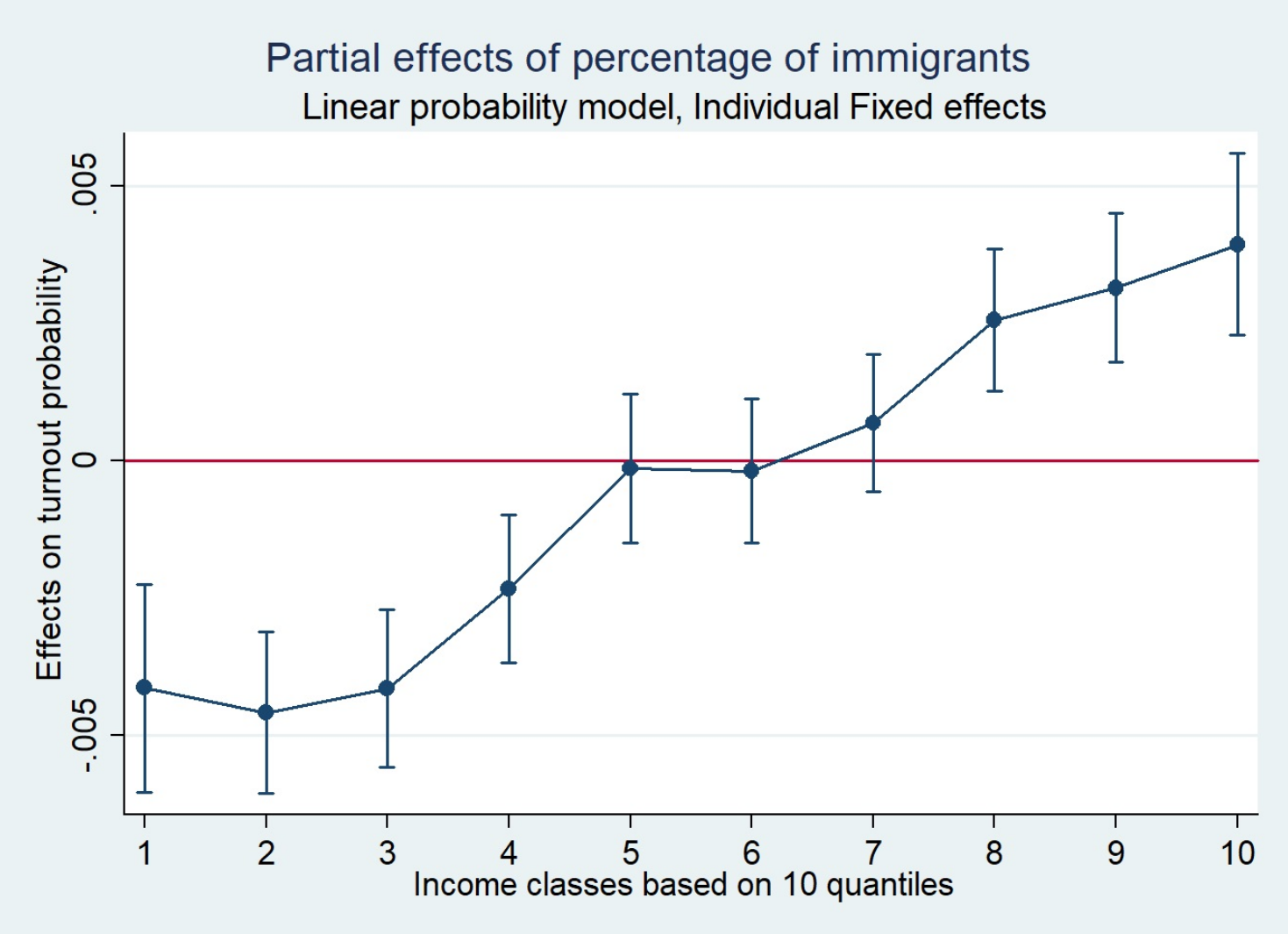

Figure 2 
In the last set of estimates, we turn to the ICFE specification, which allows us to control for individual, $a_{i}$, and contextual, $u_{c}$, unobserved time invariant heterogeneity in eq. (1). ${ }^{18}$ Although the results obtained within the ICFE specification should be considered valid only for the sub-population of non movers, as the decision of changing residence is non random in our context, this specification is still our preferred one. In fact, it delivers results that we can confidently consider as causal, as they are net of all sources of bias related to unobserved time invariant factors.

Estimation results for the heterogeneous effect of ethnic diversity across income classes are reported in Table 5 and Figure 3. The increasing pattern spotted in the full sample is confirmed for non movers. In particular, as shown in Table 5, the partial effect of ethnic heterogeneity is estimated to about -0.6 p.p. in the first two income classes, implying that the probability that an eligible voter casts a ballot in elections decreases by about 0.6 p.p. following an increase by 1 p.p. in the share of immigrants in her neighborhood. The partial effect of ethnic heterogeneity falls to about -0.5 p.p. for eligible voters in the third income class and to -0.3 p.p. in the fourth. Eligible voters in the central income classes (fifth to seventh) are found to be not significantly affected by increased neighborhood diversity. On the contrary, higher ethnic diversity produces higher political participation for individuals with equivalent income in the upper three classes, with increasing magnitude of the partial effect, up to about 0.3 p.p. in the top class. Finally, notice that the overall effect on the probability of turnout of a 1 p.p. increase in ethnic diversity is negative and equal to - 0.12 p.p., a magnitude very similar to that obtained by Bellettini et al. (2016) with aggregate data at the precinct level (- 0.14 p.p.).

Overall, our results suggest that immigration may have negative by-products on a cornerstone of representative democracy, that is electoral turnout. Not only immigration and the ensuing ethnic diversity contribute to depress overall turnout (a result already highlighted in our previous work with aggregate data, see Bellettini et al., 2016), but they also seem to saw the seeds for increased inequality in political representation, as the mobilization effect differs across the income distribution. The latter effect is potentially very insidious for the quality of democracy as it piles up on the well known lower political participation of the less affluent relative to the more resourceful, which is also confirmed by our analysis.

\footnotetext{
${ }^{18}$ Table A5 describes our variables in the sub-sample of non-movers and testifies the existence of within variation needed for the ICFE estimation strategy.
} 
Table 5. Partial effects of percentage of foreigners from Asia and Africa by income class Linear probability model - Individual and Contextual Fixed Effects (non-movers)

\begin{tabular}{ccccccc}
\hline Income class & $\mathrm{dy} / \mathrm{dx}$ & $\begin{array}{c}\text { Std. Err. } \\
\text { Delta-method }\end{array}$ & $\mathrm{z}$ & $\mathrm{P}>\mathrm{z}$ & {$[95 \%$ Conf.Interval $]$} \\
\hline 1 & -0.0062 & 0.0014 & -4.3700 & 0.0000 & -0.0090 & -0.0034 \\
2 & -0.0063 & 0.0010 & -6.1200 & 0.0000 & -0.0083 & -0.0043 \\
3 & -0.0049 & 0.0011 & -4.5100 & 0.0000 & -0.0070 & -0.0028 \\
4 & -0.0029 & 0.0009 & -3.1300 & 0.0020 & -0.0047 & -0.0011 \\
5 & -0.0004 & 0.0010 & -0.4200 & 0.6770 & -0.0023 & 0.0015 \\
6 & -0.0011 & 0.0008 & -1.3500 & 0.1770 & -0.0027 & 0.0005 \\
7 & 0.0005 & 0.0009 & 0.5400 & 0.5910 & -0.0012 & 0.0022 \\
8 & 0.0029 & 0.0009 & 3.3100 & 0.0010 & 0.0012 & 0.0046 \\
9 & 0.0031 & 0.0010 & 3.0600 & 0.0020 & 0.0011 & 0.0050 \\
10 & 0.0033 & 0.0010 & 3.2300 & 0.0010 & 0.0013 & 0.0053 \\
\hline
\end{tabular}

Number of individuals: 210,838

Individual controls: age classes, ncomp classes, city center residence, income classes

Contextual controls: precinct mean inc equiv, gini inc net equiv, pop density, perc homeown. 


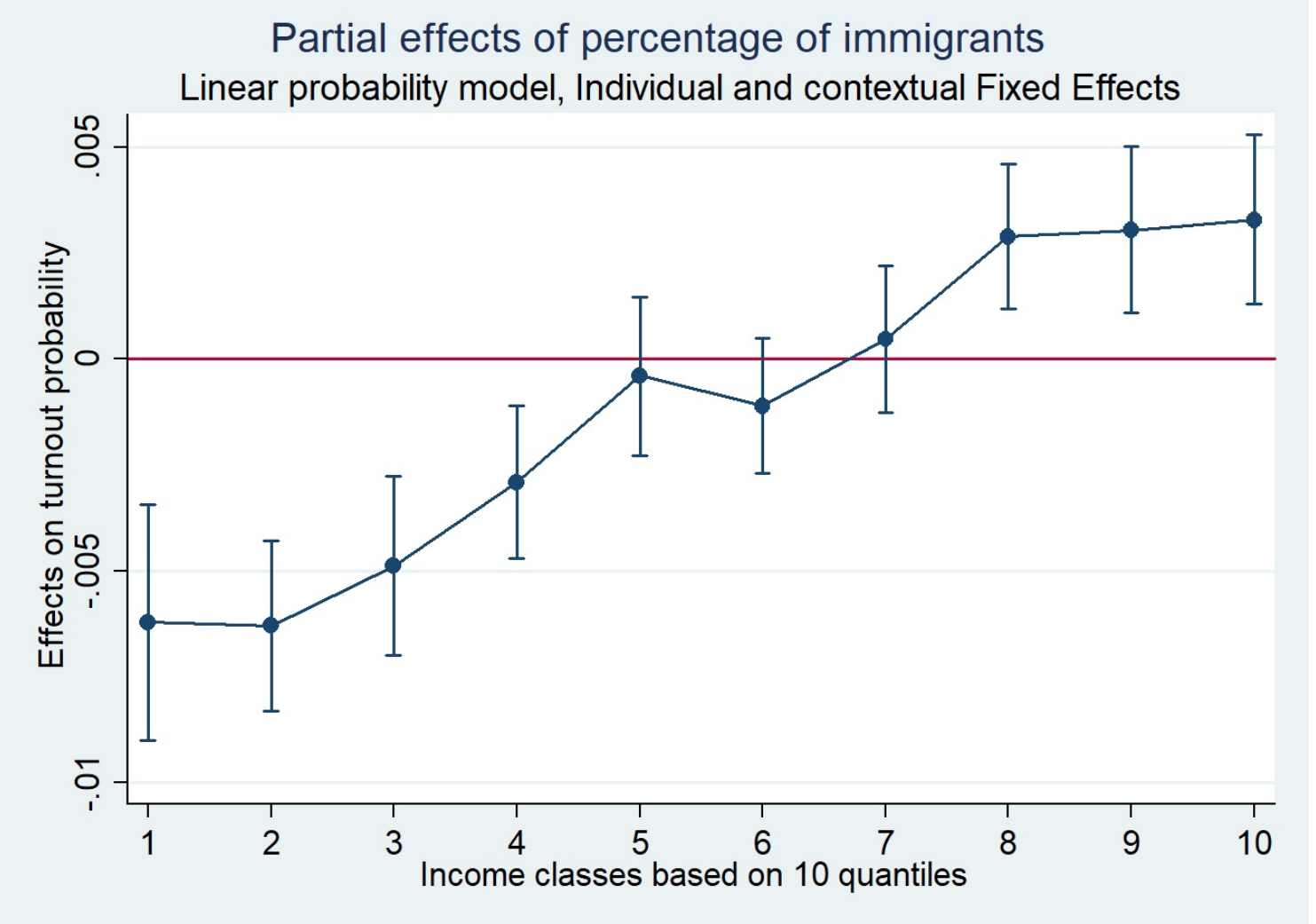

Figure 3 
Before concluding this Section, we run some regressions for the probability of changing neighborhood of residence between 2004 to 2009 as a function of ethnic diversity in the neighborhood of residence in 2004, the change in diversity experienced over the two years, individual equivalent income in 2004, and all other individual and contextual observables included in the turnout model.

Results are presented in Table A7. As shown in the last column, the decision to move depends on several individual characteristics included in our turnout model but not on contextual factors and, in particular, not on ethnic diversity in the neighborhood of origin. ${ }^{19}$ Thus, although the decision to move is not random, it does not depend on our main variable of interest, lending support to the generalizability of results obtained for non movers, in our preferred specification, to the full sample. This conclusion is corroborated by the observation that the estimation results obtained in the two samples are fairly similar, as shown by inspection of Table 4 and 5 .

\section{Sensitivity analysis}

In this section we perform a series of sensitivity analyses on our preferred ICFE model results (presented in Table 5 and Figure 3), to check their robustness to the chosen measure of ethnic diversity and to various form of misspecification. We begin by considering fragmentation as an alternative measure of ethnic diversity. We then check whether omission of educational achievement, which we do not observe in our data, is a source of bias for our estimates. Next, we estimate the ICFE model on a sample that does not include multiple member per household. Finally, we adopt a non-linear formulation for the binary response model. In the following subsections we report the partial effects of ethnic diversity estimated within each exercise and describe their patterns. Figures A1-A4 in the Appendix allow for a visual inspection of the same findings.

\subsection{Fragmentation}

So far ethnic diversity in the voter's neighborhood was measured by ethnic concentration, i.e. the percentage of resident immigrants. An alternative approach, often followed in the literature, is to consider the Herfindahl index of ethnic fragmentation that captures the

\footnotetext{
${ }^{19}$ Among the factors explaining the individual decision to change residence, the choice of leaving one's household of origin and/or forming a new one seems to be the dominant one: out of 30,753 movers, corresponding to about $13 \%$ of eligible voters in the balanced panel sample, $42 \%$ also changed household between 2004 and 2009 .
} 
number and relative size of various ethnic group in a given neighborhood:

$$
H_{c t}=1-\sum_{g=1}^{G} s_{g c t}^{2}
$$

where $s_{g c t}$ is the concentration of ethnic group $g$ in precinct $c$ at time $t(t=2004,2009)$.

The results of the ICFE specification using the Herfindal index as a measure of ethnic diversity, reported in Table 6, show that the pattern of the effect of ethnic fragmentation on turnout is qualitatively similar to that obtained using ethnic concentration. ${ }^{20}$ Again, increased ethnic fragmentation causes a drop in political participation for the less affluent, which decreases in magnitude for individuals belonging to higher income classes and becomes positive for the richest.

Table 6. Partial effects of ethnic fragmentation by income class

\begin{tabular}{ccccccc}
\hline \multicolumn{6}{c}{ Linear probability model - Individual and contextual Fixed Effects (non-movers) } \\
\hline Income class & $\mathrm{dy} / \mathrm{dx}$ & $\begin{array}{c}\text { Std. Err. } \\
\text { Delta-method }\end{array}$ & $\mathrm{z}$ & $\mathrm{P}>\mathrm{z}$ & {$[95 \%$ Conf.Interval $]$} \\
\hline 1 & -0.3357 & 0.0434 & -7.7400 & 0.0000 & -0.4208 & -0.2507 \\
2 & -0.3074 & 0.0331 & -9.2900 & 0.0000 & -0.3722 & -0.2425 \\
3 & -0.2341 & 0.0311 & -7.5300 & 0.0000 & -0.2951 & -0.1732 \\
4 & -0.1291 & 0.0305 & -4.2300 & 0.0000 & -0.1889 & -0.0692 \\
5 & -0.0239 & 0.0301 & -0.7900 & 0.4270 & -0.0829 & 0.0350 \\
6 & -0.0280 & 0.0295 & -0.9500 & 0.3430 & -0.0858 & 0.0299 \\
7 & 0.0354 & 0.0293 & 1.2100 & 0.2260 & -0.0219 & 0.0928 \\
8 & 0.1272 & 0.0290 & 4.3900 & 0.0000 & 0.0704 & 0.1839 \\
9 & 0.1530 & 0.0307 & 4.9900 & 0.0000 & 0.0929 & 0.2131 \\
10 & 0.1639 & 0.0345 & 4.7500 & 0.0000 & 0.0963 & 0.2316 \\
\hline
\end{tabular}

Number of individuals: 210,838

Individual controls: age classes, ncomp classes, city center residence, income clases

Contextual controls: precinct mean inc equiv, gini inc net equiv, pop density, perc homeown.

\footnotetext{
${ }^{20}$ The magnitudes of partial effects of concentration and fragmentation are not directly comparable to each other given the different scales of these measures.
} 


\subsection{Education}

Education has long been considered as a crucial explanation for political participation (see, for example, Nie et al., 1996, and Wolfinger and Rosenston, 1980). ${ }^{21}$ Unfortunately, education is not a reliable information in our register and official electoral lists data. To check robustness of our results, we therefore performed ICFE estimations on a sub-sample of eligible voters aged 25 and more in 2004, for whom we can assume that the educational attainment has remained constant in the subsequent five years.

Table 7. Partial effects of percentage of foreigners from Asia and Africa by income class

\begin{tabular}{ccccccc}
\hline \multicolumn{6}{c}{ Linear probability model - Individual and Contextual Fixed Effects, eligible voters aged $>25$} \\
\hline Income class & $\mathrm{dy} / \mathrm{dx}$ & $\begin{array}{c}\text { Std. Err. } \\
\text { Delta-method }\end{array}$ & $\mathrm{z}$ & $\mathrm{P}>\mathrm{z}$ & {$[95 \%$ Conf.Interval $]$} \\
\hline 1 & -0.0062 & 0.0015 & -4.0900 & 0.0000 & -0.0092 & -0.0033 \\
2 & -0.0068 & 0.0011 & -6.2300 & 0.0000 & -0.0089 & -0.0046 \\
3 & -0.0051 & 0.0011 & -4.6800 & 0.0000 & -0.0072 & -0.0030 \\
4 & -0.0035 & 0.0009 & -3.7300 & 0.0000 & -0.0054 & -0.0017 \\
5 & -0.0003 & 0.0010 & -0.2600 & 0.7910 & -0.0022 & 0.0017 \\
6 & -0.0011 & 0.0008 & -1.3400 & 0.1800 & -0.0027 & 0.0005 \\
7 & 0.0009 & 0.0009 & 1.0300 & 0.3050 & -0.0008 & 0.0026 \\
8 & 0.0031 & 0.0008 & 3.7300 & 0.0000 & 0.0015 & 0.0048 \\
9 & 0.0031 & 0.0010 & 3.0000 & 0.0030 & 0.0011 & 0.0051 \\
10 & 0.0032 & 0.0011 & 3.0300 & 0.0020 & 0.0011 & 0.0053 \\
\hline
\end{tabular}

Number of individuals: 199,263

Individual controls: age classes, ncomp classes, city center residence, income classes

Contextual controls: precinct mean inc equiv, gini inc net equiv, pop density, perc homeown.

Results in Table 7 confirm the heterogeneous effect of ethnic diversity on turnout for individuals belonging to different income classes, with pattern and the magnitude very similar to those obtained using the whole sample of non-movers. Even if we restrict attention to individuals with the same level of education, who may share similar views concerning the consequences of immigration and the relevance of political participation,

\footnotetext{
${ }^{21}$ The causal interpretation of the conventional wisdom that education positively affects turnout has been questioned in recent studies which argue that unobservable personal traits and early-life socialization within the family might have confounded the relationship in earlier contributions. In fact, some studies find evidence of a causal effect (see for example, among others, Sondheimer and Green, 2010) while others do not (see for instance Berinsky and Lenz, 2011).
} 
ethnic diversity seems to have different impact on the latter depending on income, with the more affluent being mobilized by increasing ethnic concentration in the neighborhood and the less affluent being marginalized.

\subsection{Individuals versus households in the sample}

This robustness check aims at ruling out potential inferencial problems arising from the presence of multiple members per household in the sample. To this aim, we randomly select one eligible voter per household from the sample of non-movers and re-run the ICFE estimation. Table 8 shows that the magnitude of the effects of ethnic diversity, their pattern across income classes as well as their significance are substantially unchanged with respect to the results contained in Table 5, suggesting that clustering at the household level is not undermining the validity of the inference in our main estimation results.

Table 8. Partial effects of percentage of foreigners from Asia and Africa by income class

\begin{tabular}{ccccccc}
\hline \multicolumn{6}{c}{ Linear probability model - Individual and Contextual Fixed Effects, one individual per household } \\
\hline Income class & $\mathrm{dy} / \mathrm{dx}$ & $\begin{array}{c}\text { Std. Err. } \\
\text { Delta-method }\end{array}$ & $\mathrm{z}$ & $\mathrm{P}>\mathrm{z}$ & {$[95 \%$ Conf.Interval] } \\
\hline 1 & -0.0070 & 0.0016 & -4.4200 & 0.0000 & -0.0101 & -0.0039 \\
2 & -0.0065 & 0.0013 & -5.1700 & 0.0000 & -0.0090 & -0.0040 \\
3 & -0.0047 & 0.0013 & -3.7000 & 0.0000 & -0.0073 & -0.0022 \\
4 & -0.0034 & 0.0011 & -3.2400 & 0.0010 & -0.0055 & -0.0014 \\
5 & -0.0006 & 0.0011 & -0.5400 & 0.5910 & -0.0028 & 0.0016 \\
6 & -0.0010 & 0.0010 & -1.0100 & 0.3150 & -0.0029 & 0.0009 \\
7 & 0.0003 & 0.0010 & 0.3100 & 0.7580 & -0.0017 & 0.0023 \\
8 & 0.0031 & 0.0010 & 3.0000 & 0.0030 & 0.0011 & 0.0051 \\
9 & 0.0041 & 0.0012 & 3.5400 & 0.0000 & 0.0018 & 0.0064 \\
10 & 0.0050 & 0.0012 & 4.0900 & 0.0000 & 0.0026 & 0.0073 \\
\hline
\end{tabular}

Number of individuals: 128,460

Individual controls: age classes, ncomp classes, city center residence, income classes

Contextual controls: precinct mean inc equiv, gini inc net equiv, pop density, perc homeown. 


\subsection{Non linear functional form}

We contrast here the linear probability ICFE results with those of a logit model, which entails the following non linear formulation of the response probability:

$\operatorname{Pr}\left(\right.$ turnout $\left._{i c t}=1\right)=\Lambda\left(\beta_{1}+\beta_{2}\right.$ het $_{c t}+\beta_{3}$ income $_{i t}+\sum_{j=2}^{10} \beta_{4 j}$ het $\left._{c t} * i n c_{-} j_{i t}+\beta_{5} X_{i c t}+\eta_{t}+a_{i}+u_{c}\right)$

where $\Lambda(\cdot)$ denotes the cumulative density function of the logistic distribution. Given the non linear specification and our focus on the effect of ethnic diversity we avoid here overparametrization and control for ethnic diversity with income expressed in level, rather than income class dummies as in our main model. Table 9 reports the average partial effects of ethnic diversity obtained estimating the above logit formulation by individual and contextual fixed effects. They still turn from negative to positive across income classes, with the only difference being the statistical insignificance for the top income classes. While we consider this result as further evidence in support of our general finding of heterogeneous ethnic diversity effects across income groups, as far as the numerical interpretation of the results is concerned we stick to the linear probability model discussed in the previous section, which is more flexible and robust to functional form misspecification.

Table 9. Partial effects of percentage ofimmigrants from Asia and Africa by income class

\begin{tabular}{ccccccc}
\hline \multicolumn{7}{c}{ Logit model - Individual and contextual Fixed Effects (non-movers) } \\
\hline Income class & $\mathrm{dy} / \mathrm{dx}$ & $\begin{array}{c}\text { Std. Err. } \\
\text { Delta-method }\end{array}$ & $\mathrm{z}$ & $\mathrm{P}>\mathrm{z}$ & {$[95 \%$ Conf.Interval $]$} \\
\hline 1 & -.0073101 & .0018511 & -3.95 & 0.000 & -.0109382 & -.0036819 \\
2 & -.0073809 & .0017355 & -4.25 & 0.000 & -.0107824 & -.0039794 \\
3 & -.0058905 & .0016623 & -3.54 & 0.000 & -.0091486 & -.0026323 \\
4 & -.002212 & .0015712 & -1.41 & 0.159 & -.0052916 & .0008676 \\
5 & .0013806 & .0015224 & 0.91 & 0.364 & -.0016032 & .0043645 \\
6 & -.0009583 & .0015873 & -0.60 & 0.546 & -.0040694 & .0021528 \\
7 & .0012209 & .0016424 & 0.74 & 0.457 & -.0019981 & .0044399 \\
8 & .0040335 & .0017926 & 2.25 & 0.024 & .0005201 & .0075468 \\
9 & .0032725 & .0019397 & 1.69 & 0.092 & -.0005292 & .0070742 \\
10 & .0011956 & .0022514 & 0.53 & 0.595 & -.0032171 & .0056082 \\
\hline
\end{tabular}

Number of individuals: 210,838

Individual controls: age classes, ncomp classes, city center residence, income level

Contextual controls: precinct mean inc equiv, gini inc net equiv, pop density, perc homeown. 


\section{Concluding remarks}

In the presence of massive flows of migrants and refugees, it becomes particularly important to understand the implications of increasing exposure to ethnic others for civic and prosocial behavior in receiving countries.

This paper addresses these issues by focusing on the effects of neighborhood ethnic heterogeneity on resident nationals' electoral turnout in the receiving community, that is Bologna, a medium sized municipality in Northern Italy, in our case of study. Overall, our results suggest that both individual and contextual socio-economic characteristics are important determinants of electoral participation and that increasing ethnic diversity of residential neighborhoods may be a driver of disaffection for politics among the less affluent while boosting participation among the rich, with overall negative effect on turnout. Insofar as reduced and unequal political participation translates into unequal political representation of the interests of different groups, these results point to a potential democratic deficit in increasingly diverse communities, as a by-product of immigration.

To the best of our knowledge, this paper is the first one in the literature that investigates and detects the non linear effect of diversity on individual electoral turnout via individual income. Our results, based on socio-economic characteristics and behavior of residents in an Italian municipality, highlight a possible link between immigration and political inequality, that is associated to income inequality and might be particularly pernicious for the functioning of our democracies.

To the extent that our results will be confirmed and generalized by other studies to different contexts, these results may have relevant policy implications for destination countries, such as Italy and other continental and southern European countries, which recently witnessed an upsurge of immigrants' inflows, rapidly changing the fabric of previously ethnically homogeneous societies.

\section{References}

[1] Alesina, A. and La Ferrara, E. (2000). Participation in Heterogeneous Communities. The Quarterly Journal of Economics, 115: 847-904.

[2] Alesina, A. and La Ferrara, E. (2002). Who Trusts Others?. Journal of Public Economics, 85: 207-234.

[3] Barber, M. and Imai, K. (2014). Estimating Neighborhood Effects on Turnout from Geocoded Voter Registration Records, Princeton University, mimeo. 
[4] Barone, G., D'Ignazio, A., de Blasio, G, and P. Naticchioni (2016). Mr. Rossi, Mr. $\mathrm{Hu}$ and politics. The role of immigration in shaping natives' voting behavior. Journal of Public Economics, 136: 1-13.

[5] Bellettini, G., Berti Ceroni, C., and Monfardini, C. (2016). Neighborhood Heterogeneity and Electoral Turnout. Electoral Studies, 43: 146-156.

[6] Berinsky, A. J. and Lenz, G. S. (2011). Education and Political Participation: Exploring the Causal Link. Political Behavior, 33(3): 357-373.

[7] Bhatti, Y., Hansen, K.M., and Wass, H. (2012). The Relationship between Age and Turnout: a Roller-coaster Ride. Electoral Studies, 31: 588-593.

[8] Bhatti, Y., Danckert, B. and K.M. Hansen (2016). The Context of Voting: Does Neighborhood Ethnic Diversity Affect Turnout?. Social Forces, 95: 1127-1154.

[9] Blais, A. (2000). To Vote or Not To Vote, University of Pittsburgh Press.

[10] Cancela, J. and Geys B. (2016). Explaining Voter Turnout: A Meta-analysis of National and Subnational Elections. Electoral Studies, 42: 264-275.

[11] Dinesen, P.T., and Sønderskovb, K.M. (2015). Ethnic Diversity and Social Trust: Evidence from the Micro-Context. American Sociological Review, 80(3): 550-573.

[12] Enos, R. (2016). What the Demolition of Public Houses Teaches Us about the Impact of Racial Threat on Political Behavior. American Journal of Political Science, 60: 123-142.

[13] Fieldhouse E. and Cutts D. (2008). Diversity, Density and Turnout: the Effect of Neighbourhood Ethno-religious Composition on Voter Turnout in Britain. Political Geography, 27: 530-548.

[14] Gimpel J. G., Dyck J. J., and Shaw D. R. (2004). Registrants, Voters and Turnout Variability Across Neighborhoods. Political Behavior, 26(4): 343-375.

[15] Johnson, A. (2014). Ambivalence, Political Engagement and Context. Political Studies, 62: 502-521.

[16] ISTAT (2007). La Popolazione Straniera Residente in Italia al $1^{\circ}$ Gennaio 2007. Statistiche in breve, ISTAT. 
[17] Martikainen, P., Martikainen, T., Wass, H. (2005). The Effect of Socioeconomic Factors on Voter Turnout in Finland: a Register-based Study of 2.9 Million Voters. European Journal of Political Research, 44: 645-669.

[18] Nie, N., Junn, J. and Stehlik-Barry, K. (1996). Education and Democratic Citizenship in America. University of Chicago Press.

[19] Mutz, D.C. (2002). The Consequences of Cross-Cutting Networks for Political Participation. Journal of Political Science, 46 (4): 838-855.

[20] Putnam, R. (2007). E Pluribus Unum: Diversity and Community in the Twenty-first Century. Scandinavian Political Studies, 30(2): 137-174.

[21] Smets, K. and van Ham, C. (2013). The Embarrassment of Riches? A Meta-analysis of Individual-level Research on Voter Turnout. Electoral Studies , 32(2): 344-359.

[22] Sondheimer, R. M., and Green, D. P. (2010). Using Experiments to Estimate the Effects of Education on Voter Turnout. American Journal of Political Science, 54(1): 174-189.

[23] Wolfinger, R. E., \& Rosenstone, S. J. (1980). Who Votes?. New Haven: Yale University Press. 


\section{Appendix}

Table A1. Variables' description.

\begin{tabular}{ll} 
Individual level variables & $=1$ if individual voted at election, 0 otherwise \\
voted & individual's age \\
age & Number of components of the household \\
ncomp & Household's equivalent income (Thousands Euros) \\
inc net equiv & $=1$ if female, 0 if male \\
female & $=1$ if married, 0 otherwise \\
married & $=1$ if the individual lives in the center of the city, 0 otherwise \\
city center residence & $=1$ if the individual has a foreign citizenship, 0 otherwise \\
foreign citizen & $=1$ if individual moved from another municipality, 0 otherwise \\
moved & Number of years since the individual has moved \\
years of residence & $=1$ if the individual was born outside Bologna, 0 otherwise \\
non native & \\
& $\%$ foreign residents (all non eligible voters) \\
Contextual (precinct-level) variables & $\%$ foreign residents from Asia and Africa \\
perc foreign all & Mean equivalent net income (Thousands euros) \\
perc foreign asia africa \\
precinct mean inc equiv \\
gini inc net equiv \\
$\begin{array}{l}\text { pop density } \\
\text { perc homeown }\end{array}$ \\
\hline
\end{tabular}


Table A2. Summary statistics, years 2004-2009 pooled

\begin{tabular}{|c|c|c|c|c|c|c|c|c|}
\hline & \multicolumn{4}{|c|}{ Whole sample } & \multicolumn{4}{|c|}{ Balanced panel sample } \\
\hline & Mean & Std Dev. & Min & Max & Mean & Std Dev. & Min & Max \\
\hline voted & 0.82 & 0.39 & 0 & 1 & 0.84 & 0.36 & 0 & 1 \\
\hline age & 53.7 & 19.01 & 17 & 112 & 55.03 & 17.9 & 18 & 112 \\
\hline ncomp & 2.34 & 1.15 & 1 & 17 & 2.36 & 1.12 & 1 & 17 \\
\hline inc net equiv & 21.09 & 21.8 & 0 & 3293.25 & 21.94 & 21.26 & 0 & 2761.31 \\
\hline female & 0.54 & 0.5 & 0 & 1 & 0.55 & 0.5 & 0 & 1 \\
\hline married & 0.53 & 0.5 & 0 & 1 & 0.57 & 0.5 & 0 & 1 \\
\hline city center residence & 0.14 & 0.35 & 0 & 1 & 0.14 & 0.34 & 0 & 1 \\
\hline moved & 0.67 & 0.47 & 0 & 1 & 0.66 & 0.48 & 0 & 1 \\
\hline years of residence & 20.36 & 22.25 & 0 & 100 & 21.58 & 22.32 & 0 & 100 \\
\hline foreign citizen & 0.00 & 0.05 & 0 & 1 & 0.00 & 0.02 & 0 & 1 \\
\hline non native & 0.57 & 0.5 & 0 & 1 & 0.55 & 0.5 & 0 & 1 \\
\hline perc foreign all & 7.53 & 4.79 & 0.27 & 32.87 & 7.55 & 4.79 & 0.27 & 32.87 \\
\hline perc foreign asia africa & 4.49 & 3.22 & 0 & 29.28 & 4.48 & 3.21 & 0 & 29.28 \\
\hline perc foreign east eur not eu & 1.87 & 1.24 & 0 & 12.79 & 1.87 & 1.2 & 0 & 12.79 \\
\hline precinct mean inc equiv & 18.76 & 4.21 & 10.76 & 39.32 & 18.77 & 4.19 & 10.76 & 39.32 \\
\hline gini inc net equiv & 0.4 & 0.08 & 0.25 & 0.64 & 0.4 & 0.08 & 0.25 & 0.64 \\
\hline pop density & 11.06 & 7.07 & 0.06 & 45.04 & 11.06 & 7.08 & 0.06 & 45.04 \\
\hline perc homeown & 54.49 & 12.79 & 3.98 & 89.8 & 54.64 & 12.84 & 3.98 & 89.8 \\
\hline Number of observations & 587,022 & & & & 483,182 & & & \\
\hline Number of individuals & & & & & 241,591 & & & \\
\hline
\end{tabular}


Table A3. Distribution of categorical variables, years 2004-2009 pooled. Balanced panel sample

\begin{tabular}{|c|c|c|c|c|c|c|}
\hline & & $\mathrm{N}$ & mean & St. Dev & $\min$ & $\max$ \\
\hline \multicolumn{7}{|l|}{ age class } \\
\hline & 1 & 20,161 & 22.26 & 2.27 & 18 & 25 \\
\hline & 2 & 59,113 & 31.09 & 2.82 & 26 & 35 \\
\hline & 3 & 85,220 & 40.56 & 2.85 & 36 & 45 \\
\hline & 4 & 80,321 & 50.43 & 2.90 & 46 & 55 \\
\hline & 5 & 84,120 & 60.56 & 2.87 & 56 & 65 \\
\hline & 6 & 81,104 & 70.38 & 2.85 & 66 & 75 \\
\hline & 7 & 57,346 & 79.94 & 2.75 & 76 & 85 \\
\hline & 8 & 14,869 & 88.80 & 2.54 & 86 & 95 \\
\hline & 9 & 928 & 97.64 & 1.90 & 96 & 112 \\
\hline \multicolumn{7}{|l|}{ ncomp class } \\
\hline & 1 & 119,041 & 1 & 0 & 1 & 1 \\
\hline & 2 & 168,490 & 2 & 0 & 2 & 2 \\
\hline & 3 & 117,959 & 3 & 0 & 3 & 3 \\
\hline & 4 & 61,376 & 4 & 0 & 4 & 4 \\
\hline & 5 & 12,598 & 5 & 0 & 5 & 5 \\
\hline & 6 & 2,766 & 6 & 0 & 6 & 6 \\
\hline & 7 & 952 & 7.82 & 1.76 & 7 & 17 \\
\hline \multicolumn{7}{|l|}{ income classes* } \\
\hline & 1 & 37,307 & 0.99 & 1.74 & 0.00 & 5.45 \\
\hline & 2 & 46,306 & 8.32 & 1.43 & 5.45 & 10.48 \\
\hline & 3 & 48,099 & 12.02 & 0.82 & 10.48 & 13.38 \\
\hline & 4 & 48,884 & 14.64 & 0.72 & 13.38 & 15.87 \\
\hline & 5 & 49,278 & 17.06 & 0.69 & 15.87 & 18.25 \\
\hline & 6 & 49,842 & 19.51 & 0.74 & 18.26 & 20.82 \\
\hline & 7 & 50,189 & 22.26 & 0.86 & 20.82 & 23.78 \\
\hline & 8 & 50,712 & 25.73 & 1.20 & 23.79 & 27.99 \\
\hline & 9 & 51,034 & 31.52 & 2.38 & 27.99 & 36.37 \\
\hline & 10 & 51,531 & 59.04 & 45.70 & 36.37 & 2761.31 \\
\hline Number of observations & & 483,182 & & & & \\
\hline
\end{tabular}

* Based on deciles of income distribution evaluated with the unbalanced panel sample 
Table A4. Summary statistics by year and variation across years. Balanced panel sample.

\begin{tabular}{|c|c|c|c|c|c|c|c|c|c|}
\hline & \multicolumn{4}{|c|}{2004} & \multicolumn{4}{|c|}{2009} & \multirow[t]{2}{*}{ Ratio* } \\
\hline & Mean & Std Dev. & Min & Max & Mean & Std Dev. & Min & $\operatorname{Max}$ & \\
\hline voted & 0.88 & 0.33 & 0 & 1 & 0.81 & 0.39 & 0 & 1 & 0.56 \\
\hline age & 52.58 & 17.73 & 18 & 107 & 57.49 & 17.73 & 22 & 112 & 0.14 \\
\hline ncomp & 2.44 & 1.14 & 1 & 15 & 2.29 & 1.11 & 1 & 17 & 0.35 \\
\hline inc net equiv & 22.23 & 21.61 & 0 & 2396.51 & 21.65 & 20.9 & 0 & 2761.31 & 0.39 \\
\hline female & 0.55 & 0.5 & 0 & 1 & 0.55 & 0.5 & 0 & 1 & 0.00 \\
\hline married & 0.57 & 0.49 & 0 & 1 & 0.56 & 0.5 & 0 & 1 & 0.27 \\
\hline city center residence & 0.14 & 0.35 & 0 & 1 & 0.13 & 0.34 & 0 & 1 & 0.22 \\
\hline moved & 0.65 & 0.48 & 0 & 1 & 0.66 & 0.47 & 0 & 1 & 0.05 \\
\hline years of residence & 19.95 & 21.41 & 0 & 95 & 23.22 & 23.08 & 0 & 100 & 0.09 \\
\hline foreign citizen & 0 & 0.02 & 0 & 1 & 0 & 0.02 & 0 & 1 & 0.00 \\
\hline non native & 0.55 & 0.5 & 0 & 1 & 0.55 & 0.5 & 0 & 1 & 0.00 \\
\hline perc foreign all & 4.82 & 3.04 & 0.27 & 31.49 & 10.28 & 4.67 & 1.58 & 32.87 & 0.67 \\
\hline perc foreign asia africa & 3.54 & 2.61 & 0 & 29.28 & 5.42 & 3.47 & 0 & 25.91 & 0.49 \\
\hline perc foreign east eur not eu & 1.5 & 1.1 & 0 & 12.79 & 2.25 & 1.19 & 0.12 & 8.38 & 0.54 \\
\hline precinct mean inc equiv & 19.3 & 4.23 & 10.94 & 36.11 & 18.24 & 4.09 & 10.76 & 39.32 & 0.27 \\
\hline gini inc net equiv & 0.38 & 0.08 & 0.25 & 0.64 & 0.41 & 0.08 & 0.27 & 0.64 & 0.29 \\
\hline pop density & 11.08 & 7.09 & 0.06 & 45.04 & 11.05 & 7.07 & 0.07 & 45.04 & 0.24 \\
\hline perc homeown & 56.46 & 13.33 & 3.98 & 89.8 & 52.82 & 12.05 & 4.36 & 85.64 & 0.31 \\
\hline Number of observations & 241,591 & & & & & & & & \\
\hline
\end{tabular}

${ }^{*}$ Ratio of within and overall variation 
Table A4-cont. Summary statistics by year and variation across years. Balanced panel sample

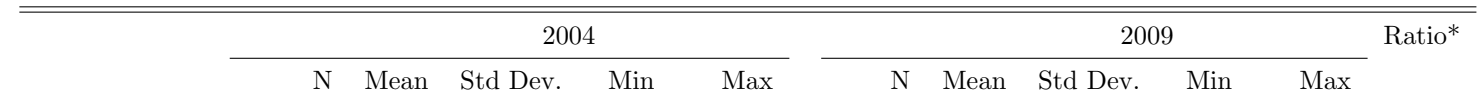

age class

$\begin{array}{rrrrrrrrrrr}14,790 & 21.65 & 2.30 & 18 & 25 & 5,371 & 23.97 & 0.86 & 22 & 25 & 0.49 \\ 34,777 & 31.02 & 2.77 & 26 & 35 & 24,336 & 31.18 & 2.88 & 26 & 35 & 0.53 \\ 43,039 & 40.46 & 2.83 & 36 & 45 & 42,181 & 40.66 & 2.87 & 36 & 45 & 0.54 \\ 39,322 & 50.47 & 2.93 & 46 & 55 & 40,999 & 50.39 & 2.87 & 46 & 55 & 0.54 \\ 43,368 & 60.52 & 2.94 & 56 & 65 & 40,752 & 60.60 & 2.80 & 56 & 65 & 0.54 \\ 38,713 & 70.33 & 2.87 & 66 & 75 & 42,391 & 70.42 & 2.82 & 66 & 75 & 0.54 \\ 24,030 & 79.60 & 2.62 & 76 & 85 & 33,316 & 80.19 & 2.82 & 76 & 85 & 0.51 \\ 3,469 & 88.89 & 2.26 & 86 & 95 & 11,400 & 88.77 & 2.62 & 86 & 95 & 0.57 \\ 83 & 97.13 & 1.65 & 96 & 107 & 845 & 97.69 & 1.92 & 96 & 112 & 0,64\end{array}$

ncomp class

$\begin{array}{rrrrrrrrrrr}54,259 & 1 & 0 & 1 & 1 & 64,782 & 1 & 0 & 1 & 1 & 0.38 \\ 81,473 & 2 & 0 & 2 & 2 & 87,017 & 2 & 0 & 2 & 2 & 0.44 \\ 63,434 & 3 & 0 & 3 & 3 & 54,525 & 3 & 0 & 3 & 3 & 0.48 \\ 33,327 & 4 & 0 & 4 & 4 & 28,049 & 4 & 0 & 4 & 4 & 0.45 \\ 7,002 & 5 & 0 & 5 & 5 & 5,596 & 5 & 0 & 5 & 5 & 0.49 \\ 1,546 & 6 & 0 & 6 & 6 & 1,220 & 6 & 0 & 6 & 6 & 0.53 \\ 550 & 7.76 & 1.58 & 7 & 15 & 402 & 7.91 & 2 & 7 & 17 & 0.51\end{array}$

income classes

\begin{tabular}{rrrrrrrrrrrrr}
1 & 17,973 & 1.00 & 1.75 & 0.00 & 5.45 & 19,334 & 0.98 & 1.73 & 0.00 & 5.44 & 0.53 \\
2 & 22,603 & 8.32 & 1.42 & 5.45 & 10.48 & 23,703 & 8.32 & 1.43 & 5.45 & 10.48 & 0.55 & \\
3 & 23,584 & 12.02 & 0.82 & 10.48 & 13.38 & 24,515 & 12.02 & 0.82 & 10.48 & 13.38 & 0.56 \\
4 & 23,758 & 14.63 & 0.72 & 13.38 & 15.87 & 25,126 & 14.64 & 0.72 & 13.38 & 15.87 & 0.58 \\
5 & 24,469 & 17.06 & 0.69 & 15.87 & 18.25 & 24,809 & 17.06 & 0.69 & 15.87 & 18.25 & 0.59 \\
6 & 25,420 & 19.52 & 0.74 & 18.26 & 20.82 & 24,422 & 19.51 & 0.74 & 18.26 & 20.82 & 0.61 \\
7 & 25,599 & 22.26 & 0.86 & 20.82 & 23.78 & 24,590 & 22.26 & 0.85 & 20.82 & 23.78 & 0.61 \\
8 & 25,595 & 25.74 & 1.20 & 23.79 & 27.99 & 25,117 & 25.73 & 1.21 & 23.79 & 27.99 & 0.60 \\
9 & 26,062 & 31.53 & 2.37 & 27.99 & 36.37 & 24,972 & 31.50 & 2.38 & 27.99 & 36.37 & 0.56 \\
10 & 26,528 & 59.20 & 46.16 & 36.37 & 2396.51 & 25,003 & 58.87 & 45.20 & 36.37 & 2761.31 & 0.41 \\
\hline Number of obs. & 241,591 & & & & & & & & & \\
\hline \hline
\end{tabular}

${ }^{*}$ Ratio of within and overall variation 
Table A5. Summary statistics by year and variation across years. Balanced panel sample. Non movers

\begin{tabular}{|c|c|c|c|c|c|c|c|c|c|}
\hline & \multicolumn{4}{|c|}{2004} & \multicolumn{4}{|c|}{2009} & \multirow{2}{*}{ Ratio* } \\
\hline & Mean & Std Dev. & Min & Max & Mean & Std Dev. & Min & Max & \\
\hline voted & 0.88 & 0.32 & 0 & 1 & 0.81 & 0.39 & 0 & 1 & 0.56 \\
\hline age & 54.11 & 17.47 & 18 & 107 & 59.02 & 17.47 & 22 & 112 & 0.14 \\
\hline ncomp & 2.44 & 1.12 & 1 & 15 & 2.31 & 1.1 & 1 & 17 & 0.30 \\
\hline inc net equiv & 22.39 & 21.56 & 0 & 2396.51 & 21.88 & 21.15 & 0 & 2761.31 & 0.37 \\
\hline female & 0.55 & 0.5 & 0 & 1 & 0.55 & 0.5 & 0 & 1 & 0.00 \\
\hline married & 0.59 & 0.49 & 0 & 1 & 0.57 & 0.49 & 0 & 1 & 0.26 \\
\hline city center residence & 0.13 & 0.34 & 0 & 1 & 0.13 & 0.34 & 0 & 1 & 0.00 \\
\hline moved & 0.66 & 0.47 & 0 & 1 & 0.66 & 0.47 & 0 & 1 & 0.04 \\
\hline years of residence & 21.15 & 21.75 & 0 & 95 & 24.44 & 23.47 & 0 & 100 & 0.09 \\
\hline foreign citizen & 0 & 0.02 & 0 & 1 & 0 & 0.02 & 0 & 1 & 0.00 \\
\hline non native & 0.56 & 0.5 & 0 & 1 & 0.56 & 0.5 & 0 & 1 & 0.00 \\
\hline perc foreign all & 4.77 & 3.02 & 0.27 & 31.49 & 10.25 & 4.66 & 1.58 & 32.87 & 0.66 \\
\hline perc foreign asia africa & 3.5 & 2.6 & 0 & 29.28 & 5.4 & 3.46 & 0 & 25.91 & 0.46 \\
\hline perc foreign east eur not eu & 1.5 & 1.1 & 0 & 12.79 & 2.25 & 1.19 & 0.12 & 8.38 & 0.52 \\
\hline precinct mean inc equiv & 19.28 & 4.21 & 10.94 & 36.11 & 18.24 & 4.07 & 10.76 & 39.32 & 0.18 \\
\hline gini inc net equiv & 0.38 & 0.08 & 0.25 & 0.64 & 0.41 & 0.08 & 0.27 & 0.64 & 0.22 \\
\hline pop density & 11.03 & 7.11 & 0.06 & 45.04 & 11.04 & 7.09 & 0.07 & 45.04 & 0.05 \\
\hline perc homeown & 56.68 & 13.32 & 3.98 & 89.8 & 52.97 & 11.99 & 4.36 & 85.64 & 0.23 \\
\hline Number of obs. & 210,838 & & & & & & & & \\
\hline
\end{tabular}

${ }^{*}$ Ratio of within and overall variation 
Table A5-cont. Summary statistics by year and variation across years. Balanced panel sample. Non movers

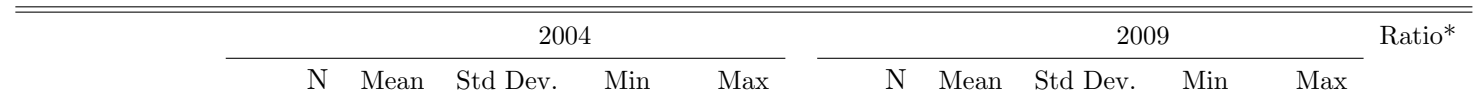

age class

$\begin{array}{rrrrrrrrrrr}11,575 & 21.45 & 2.29 & 18 & 25 & 4,603 & 23.95 & 0.86 & 22 & 25 & 0.47 \\ 24,574 & 31.17 & 2.76 & 26 & 35 & 16,921 & 31.03 & 2.95 & 26 & 35 & 0.54 \\ 35,981 & 40.56 & 2.82 & 36 & 45 & 32,707 & 40.81 & 2.86 & 36 & 45 & 0.53 \\ 35,431 & 50.52 & 2.93 & 46 & 55 & 35,924 & 50.44 & 2.87 & 46 & 55 & 0.55 \\ 40,383 & 60.54 & 2.94 & 56 & 65 & 37,509 & 60.63 & 2.79 & 56 & 65 & 0.54 \\ 36,603 & 70.33 & 2.87 & 66 & 75 & 39,861 & 70.43 & 2.82 & 66 & 75 & 0.55 \\ 22,916 & 79.60 & 2.62 & 76 & 85 & 31,636 & 80.20 & 2.81 & 76 & 85 & 0.52 \\ 3,295 & 88.88 & 2.26 & 86 & 95 & 10,876 & 88.76 & 2.62 & 86 & 95 & 0.57 \\ 80 & 97.16 & 1.67 & 96 & 107 & 801 & 97.69 & 1.94 & 96 & 112 & 0.64\end{array}$

ncomp class

$\begin{array}{rrrrrrrrrrrr}1 & 45,666 & 1 & 0 & 1 & 1 & 53,549 & 1 & 0 & 1 & 1 & 0.34 \\ 2 & 73,579 & 2 & 0 & 2 & 2 & 78,278 & 2 & 0 & 2 & 2 & 0.42 \\ 3 & 55,329 & 3 & 0 & 3 & 3 & 48,280 & 3 & 0 & 3 & 3 & 0.46 \\ 4 & 28,625 & 4 & 0 & 4 & 4 & 24,473 & 4 & 0 & 4 & 4 & 0.43 \\ 5 & 5,932 & 5 & 0 & 5 & 5 & 4,849 & 5 & 0 & 5 & 5 & 0.47 \\ 6 & 1,281 & 6 & 0 & 6 & 6 & 1,067 & 6 & 0 & 6 & 6 & 0.51 \\ 7 & 426 & 7.79 & 1.64 & 7 & 15 & 342 & 7.92 & 2.14 & 7 & 17 & 0.49\end{array}$

income classes

\begin{tabular}{rrrrrrrrrrrrr}
1 & 14,114 & 1.01 & 1.77 & 0.00 & 5.45 & 15,118 & 1.02 & 1.76 & 0.00 & 5.44 & 0.52 \\
2 & 19,444 & 8.34 & 1.41 & 5.45 & 10.48 & 20,389 & 8.33 & 1.43 & 5.45 & 10.48 & 0.54 & \\
3 & 20,890 & 12.02 & 0.82 & 10.48 & 13.38 & 21,714 & 12.03 & 0.82 & 10.48 & 13.38 & 0.55 \\
4 & 21,032 & 14.63 & 0.72 & 13.38 & 15.87 & 22,328 & 14.64 & 0.72 & 13.38 & 15.87 & 0.57 \\
5 & 21,690 & 17.06 & 0.69 & 15.87 & 18.25 & 21,943 & 17.06 & 0.69 & 15.87 & 18.25 & 0.58 \\
6 & 22,588 & 19.52 & 0.74 & 18.26 & 20.82 & 21,591 & 19.51 & 0.74 & 18.26 & 20.82 & 0.60 \\
7 & 22,560 & 22.25 & 0.86 & 20.82 & 23.78 & 21,614 & 22.26 & 0.85 & 20.82 & 23.78 & 0.60 \\
8 & 22,493 & 25.73 & 1.20 & 23.79 & 27.99 & 22,083 & 25.73 & 1.21 & 23.79 & 27.99 & 0.59 \\
9 & 22,778 & 31.54 & 2.37 & 27.99 & 36.37 & 21,958 & 31.50 & 2.38 & 27.99 & 36.37 & 0.55 \\
10 & 23,259 & 59.14 & 46.17 & 36.37 & 2396.51 & 22,100 & 59.01 & 46.06 & 36.37 & 2761.31 & 0.39 \\
\hline Number of obs. & 210,838 & & & & & & & & & \\
\hline \hline
\end{tabular}

${ }^{*}$ Ratio of within and overall variation 
Table A6. Turnout linear probability models. Pooled OLS Results. Foreigners from Asia and Africa

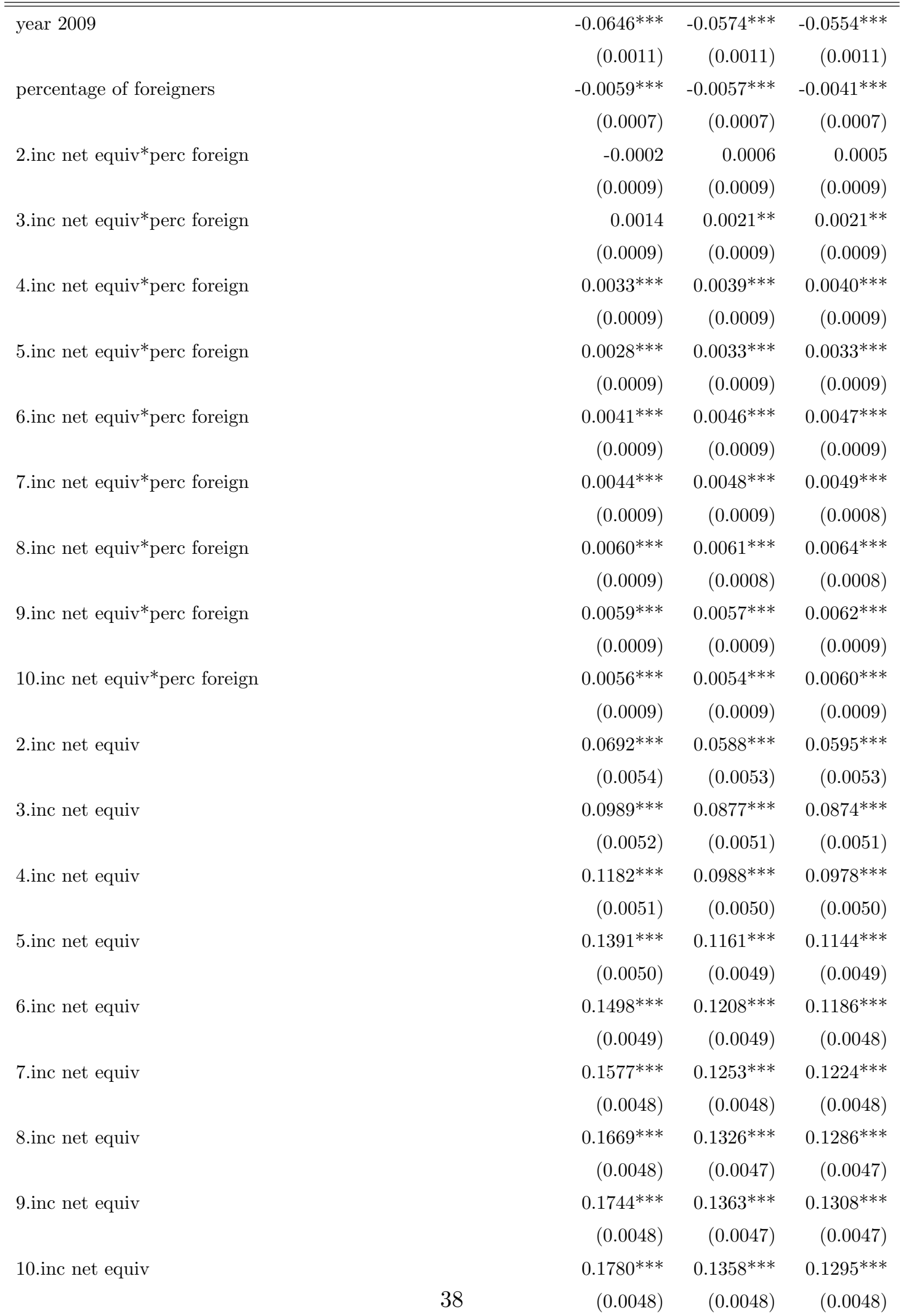


Table A6-cont. Turnout linear probability models. Pooled OLS Results. Foreigners from Asia and Africa

\begin{tabular}{|c|c|c|}
\hline 2.age & $\begin{array}{r}-0.0215^{* * *} \\
(0.0032)\end{array}$ & $\begin{array}{r}-0.0212^{* * *} \\
(0.0032)\end{array}$ \\
\hline \multirow[t]{2}{*}{ 3.age } & $0.0054^{*}$ & $0.0060^{*}$ \\
\hline & $(0.0031)$ & $(0.0031)$ \\
\hline \multirow[t]{2}{*}{ 4.age } & $0.0343^{* * *}$ & $0.0355^{* * *}$ \\
\hline & $(0.0031)$ & $(0.0031)$ \\
\hline \multirow[t]{2}{*}{ 5.age } & $0.0369^{* * *}$ & $0.0377^{* * *}$ \\
\hline & $(0.0032)$ & $(0.0032)$ \\
\hline \multirow[t]{2}{*}{ 6.age } & $0.0304^{* * *}$ & $0.0309^{* * *}$ \\
\hline & $(0.0033)$ & $(0.0033)$ \\
\hline \multirow[t]{2}{*}{ 7.age } & $-0.0488^{* * *}$ & $-0.0481^{* * *}$ \\
\hline & $(0.0036)$ & $(0.0036)$ \\
\hline \multirow[t]{2}{*}{ 8.age } & $-0.2932^{* * *}$ & $-0.2924^{* * *}$ \\
\hline & $(0.0051)$ & $(0.0051)$ \\
\hline \multirow[t]{2}{*}{ 9.age } & $-0.6029^{* * *}$ & $-0.6030^{* * *}$ \\
\hline & $(0.0132)$ & $(0.0132)$ \\
\hline \multirow[t]{2}{*}{ 2.ncomp } & $0.0031^{*}$ & $0.0031^{*}$ \\
\hline & $(0.0017)$ & $(0.0017)$ \\
\hline \multirow[t]{2}{*}{ 3.ncomp } & $0.0028 ?$ & 0.0025 \\
\hline & $(0.0018)$ & $(0.0018)$ \\
\hline \multirow[t]{2}{*}{ 4.ncomp } & $0.0106^{* * *}$ & $0.0102^{* * *}$ \\
\hline & $(0.0021)$ & $(0.0021)$ \\
\hline \multirow[t]{2}{*}{ 5.ncomp } & $-0.0088^{* *}$ & $-0.0089^{* *}$ \\
\hline & $(0.0035)$ & $(0.0035)$ \\
\hline \multirow[t]{2}{*}{ 6.ncomp } & $-0.0208^{* * *}$ & $-0.0207^{* * *}$ \\
\hline & $(0.0071)$ & $(0.0071)$ \\
\hline \multirow[t]{2}{*}{ 7.ncomp } & $-0.1251^{* * *}$ & $-0.1233^{* * *}$ \\
\hline & $(0.0141)$ & $(0.0140)$ \\
\hline
\end{tabular}


Table A6-cont. Turnout linear probability models. Pooled OLS Results. Foreigners from Asia and Africa

\begin{tabular}{|c|c|c|c|}
\hline female & & $\begin{array}{l}-0.0047^{* * *} \\
(0.0010)\end{array}$ & $\begin{array}{c}-0.0047^{* * *} \\
(0.0010)\end{array}$ \\
\hline married & & $\begin{array}{c}0.0495^{* * *} \\
(0.0014)\end{array}$ & $\begin{array}{c}0.0483^{* * *} \\
(0.0014)\end{array}$ \\
\hline city-center residence & & $\begin{array}{c}0.0048^{* * *} \\
(0.0015)\end{array}$ & $\begin{array}{c}0.0115^{* * *} \\
(0.0020)\end{array}$ \\
\hline foreign citizien & & $\begin{array}{c}-0.0752^{* *} \\
(0.0382)\end{array}$ & $\begin{array}{c}-0.0755^{* *} \\
(0.0384)\end{array}$ \\
\hline moved & & $\begin{array}{c}-0.0509^{* * *} \\
(0.0019)\end{array}$ & $\begin{array}{c}-0.0506^{* * *} \\
(0.0019)\end{array}$ \\
\hline moved*years of residence & & $\begin{array}{c}0.0012^{* * *} \\
(0.0000)\end{array}$ & $\begin{array}{c}0.0012^{* * *} \\
(0.0000)\end{array}$ \\
\hline non native & & $\begin{array}{c}-0.0238^{* * *} \\
(0.0015)\end{array}$ & $\begin{array}{c}-0.0236^{* * *} \\
(0.0015)\end{array}$ \\
\hline precinct mean inc equiv & & & $\begin{array}{c}0.0018^{* * *} \\
(0.0002)\end{array}$ \\
\hline gini inc net equiv & & & $\begin{array}{c}-0.0525^{* * *} \\
(0.0125)\end{array}$ \\
\hline pop density & & & $\begin{array}{c}0.0003^{* * *} \\
(0.0001)\end{array}$ \\
\hline perc homeown & & & $\begin{array}{c}0.0006^{* * *} \\
(0.0001)\end{array}$ \\
\hline Constant & $\begin{array}{c}0.7578^{* * *} \\
(0.0042)\end{array}$ & $\begin{array}{c}0.7689^{* * *} \\
(0.0050)\end{array}$ & $\begin{array}{c}0.7120^{* * *} \\
(0.0073)\end{array}$ \\
\hline $\begin{array}{l}\text { R-squared } \\
\text { Number of observations }\end{array}$ & $\begin{array}{c}0.0377 \\
483,182\end{array}$ & 0.0806 & 0.0814 \\
\hline
\end{tabular}

Robust S.E in brackets^

${ }^{*} \mathrm{p}<0.10,{ }^{* *} \mathrm{p}<0.05,{ }^{* * *} \mathrm{p}<0.01$

We checked that clustering at the precinct or at the family level does not alter the significance of the coefficients 
Table A7. Probability of moving between 2004 and 2009.

\begin{tabular}{|c|c|c|c|c|c|c|}
\hline \multirow[t]{2}{*}{ perc foreign asia africa 2004} & $0.0055^{*}$ & $0.0053^{*}$ & $0.0054^{*}$ & $0.0052^{*}$ & 0.0021 & 0.0019 \\
\hline & $(0.0029)$ & $(0.0028)$ & $(0.0029)$ & $(0.0028)$ & $(0.0028)$ & $(0.0026)$ \\
\hline \multirow[t]{2}{*}{ change 2004-2009 in perc } & & -0.0021 & & -0.0024 & & -0.0014 \\
\hline & & $(0.0025)$ & & $(0.0025)$ & & $(0.0026)$ \\
\hline \multirow[t]{2}{*}{ inc net equiv 2004} & & & $-0.0003^{* * *}$ & $-0.0003^{* * *}$ & $-0.0003^{* * *}$ & $-0.0003^{* * *}$ \\
\hline & & & $(0.0001)$ & $(0.0001)$ & $(0.0001)$ & $(0.0001)$ \\
\hline \multirow[t]{2}{*}{ age 2004} & & & & & $-0.0043^{* * *}$ & $-0.0043^{* * *}$ \\
\hline & & & & & $(0.0001)$ & $(0.0001)$ \\
\hline \multirow[t]{2}{*}{ ncomp 2004} & & & & & $-0.0102^{* * *}$ & $-0.0102^{* * *}$ \\
\hline & & & & & $(0.0012)$ & $(0.0012)$ \\
\hline \multirow[t]{2}{*}{ female } & & & & & $-0.0077^{* * *}$ & $-0.0077^{* * *}$ \\
\hline & & & & & $(0.0011)$ & $(0.0011)$ \\
\hline \multirow[t]{2}{*}{ married 2004} & & & & & $-0.0339^{* * *}$ & $-0.0340 * * *$ \\
\hline & & & & & $(0.0022)$ & $(0.0022)$ \\
\hline \multirow[t]{2}{*}{ city center 2004} & & & & & 0.0050 & 0.0031 \\
\hline & & & & & $(0.0188)$ & $(0.0196)$ \\
\hline \multirow[t]{2}{*}{ foreign citizien } & & & & & 0.0054 & 0.0049 \\
\hline & & & & & $(0.0502)$ & $(0.0502)$ \\
\hline \multirow[t]{2}{*}{ non native } & & & & & $0.0236^{* * *}$ & $0.0237^{* * *}$ \\
\hline & & & & & $(0.0019)$ & $(0.0019)$ \\
\hline \multirow[t]{2}{*}{ precinct mean inc 2004} & & & & & -0.0005 & -0.0008 \\
\hline & & & & & $(0.0021)$ & $(0.0022)$ \\
\hline \multirow[t]{2}{*}{ precinct gini 2004} & & & & & 0.1967 & 0.2009 \\
\hline & & & & & $(0.1414)$ & $(0.1434)$ \\
\hline \multirow[t]{2}{*}{ pop density 2004} & & & & & 0.0006 & 0.0007 \\
\hline & & & & & $(0.0008)$ & $(0.0008)$ \\
\hline \multirow[t]{2}{*}{ perc homeowner 2004} & & & & & -0.0001 & -0.0001 \\
\hline & & & & & $(0.0005)$ & $(0.0005)$ \\
\hline \multirow[t]{2}{*}{ Constant } & $0.1079^{* * *}$ & $0.1126^{* * *}$ & $0.1142^{* * *}$ & $0.1201^{* * *}$ & $0.3225^{* * *}$ & $0.3306^{* * *}$ \\
\hline & $(0.0100)$ & $(0.0072)$ & $(0.0102)$ & $(0.0071)$ & $(0.0517)$ & $(0.0518)$ \\
\hline R-squared & 0.0018 & 0.0021 & 0.0021 & 0.0025 & 0.0617 & 0.0618 \\
\hline Number of observations & 241,591 & & & & & \\
\hline
\end{tabular}

Robust S.E.in brackets

$* \mathrm{p}<0.10, * * \mathrm{p}<0.05, * * * \mathrm{p}<0.01$ 


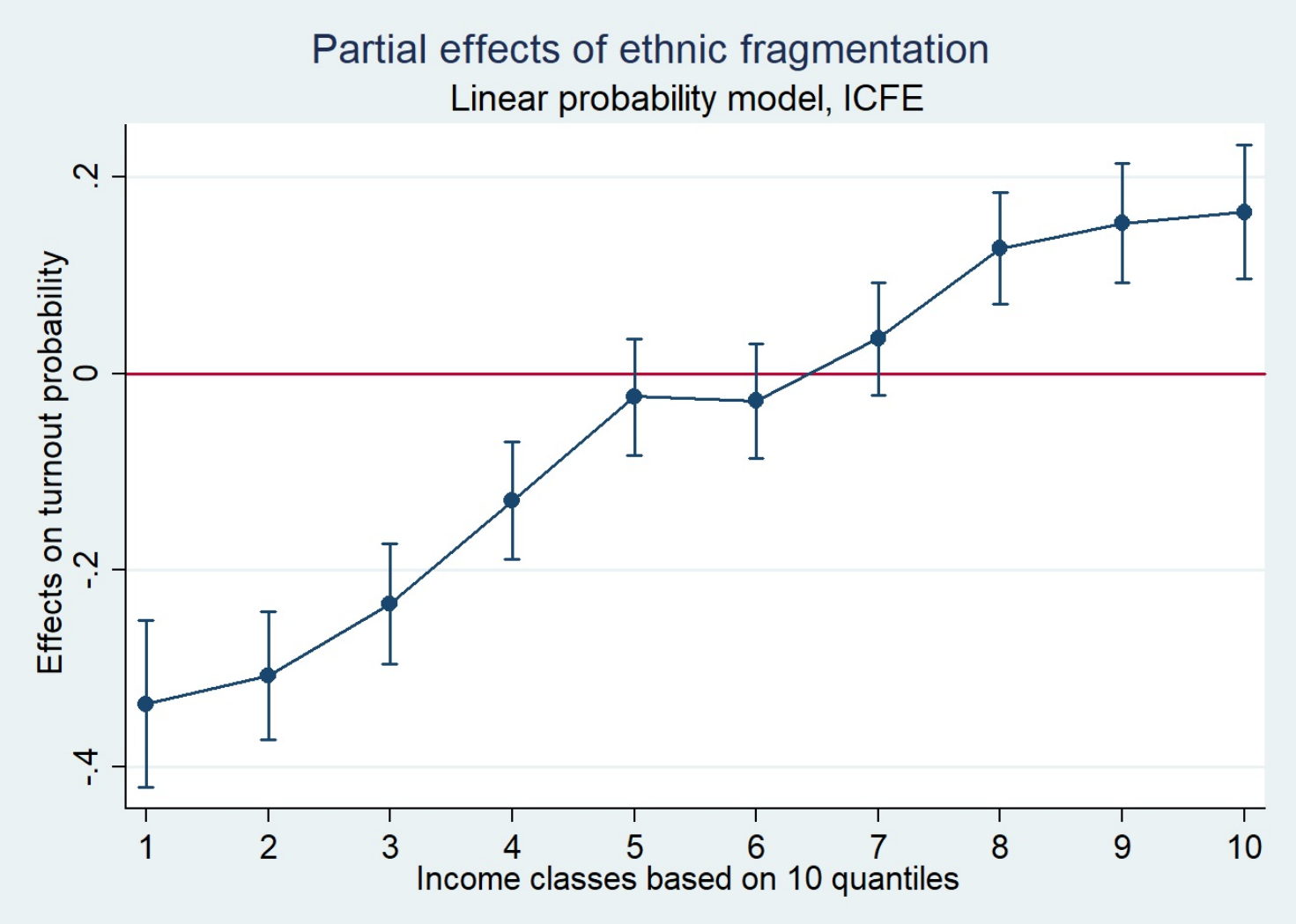

Figure A1 


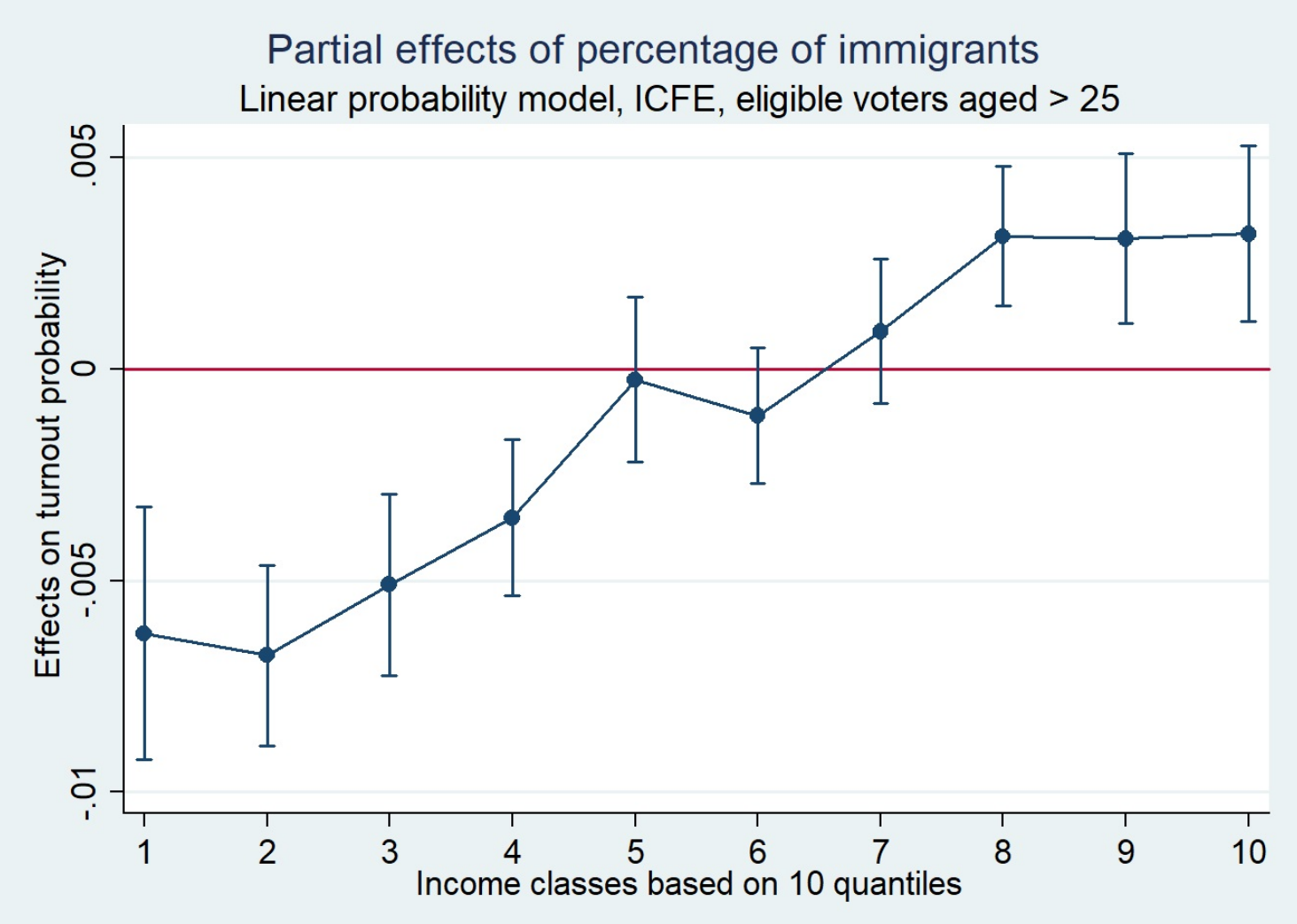

Figure A2 


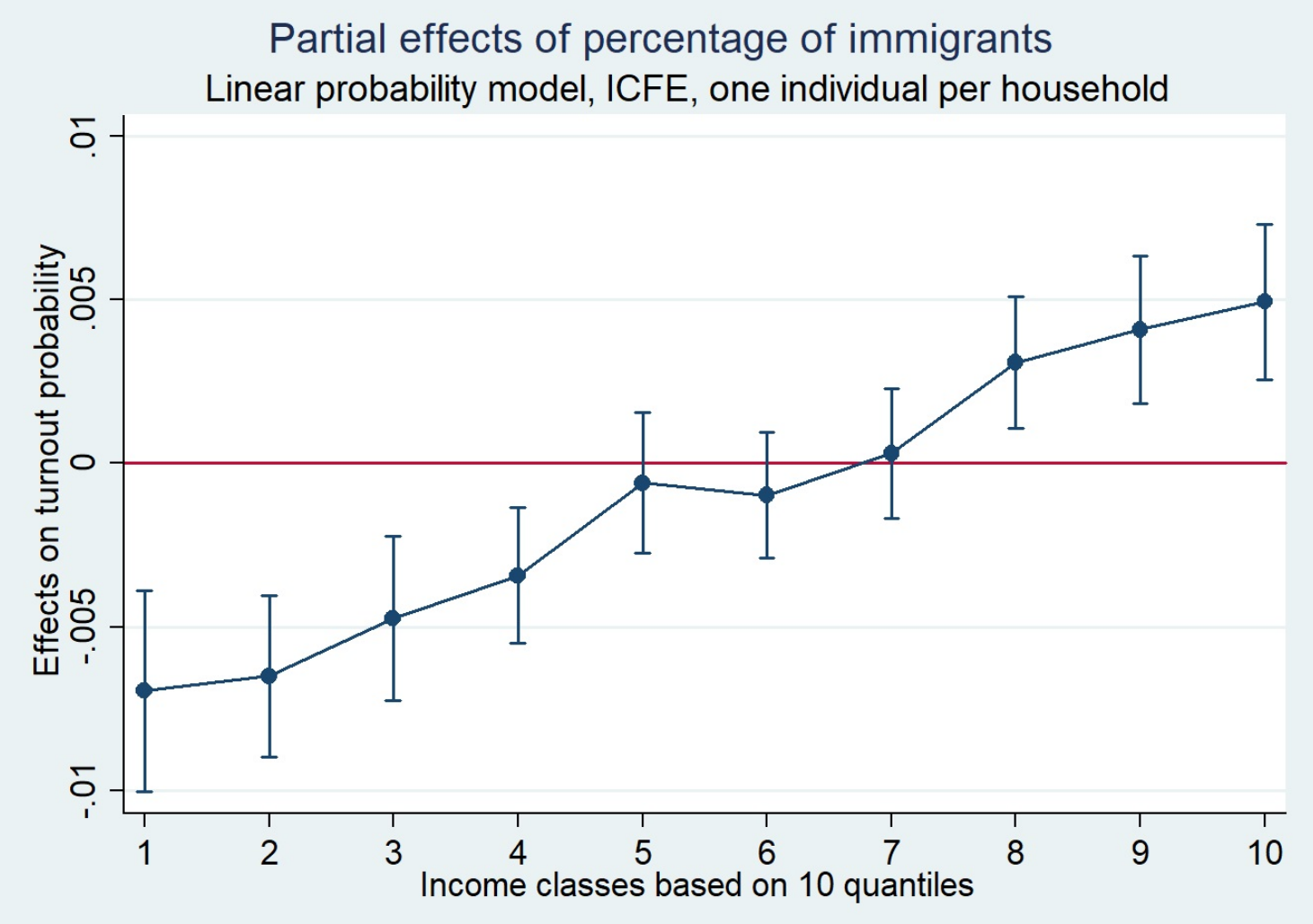

Figure A3 


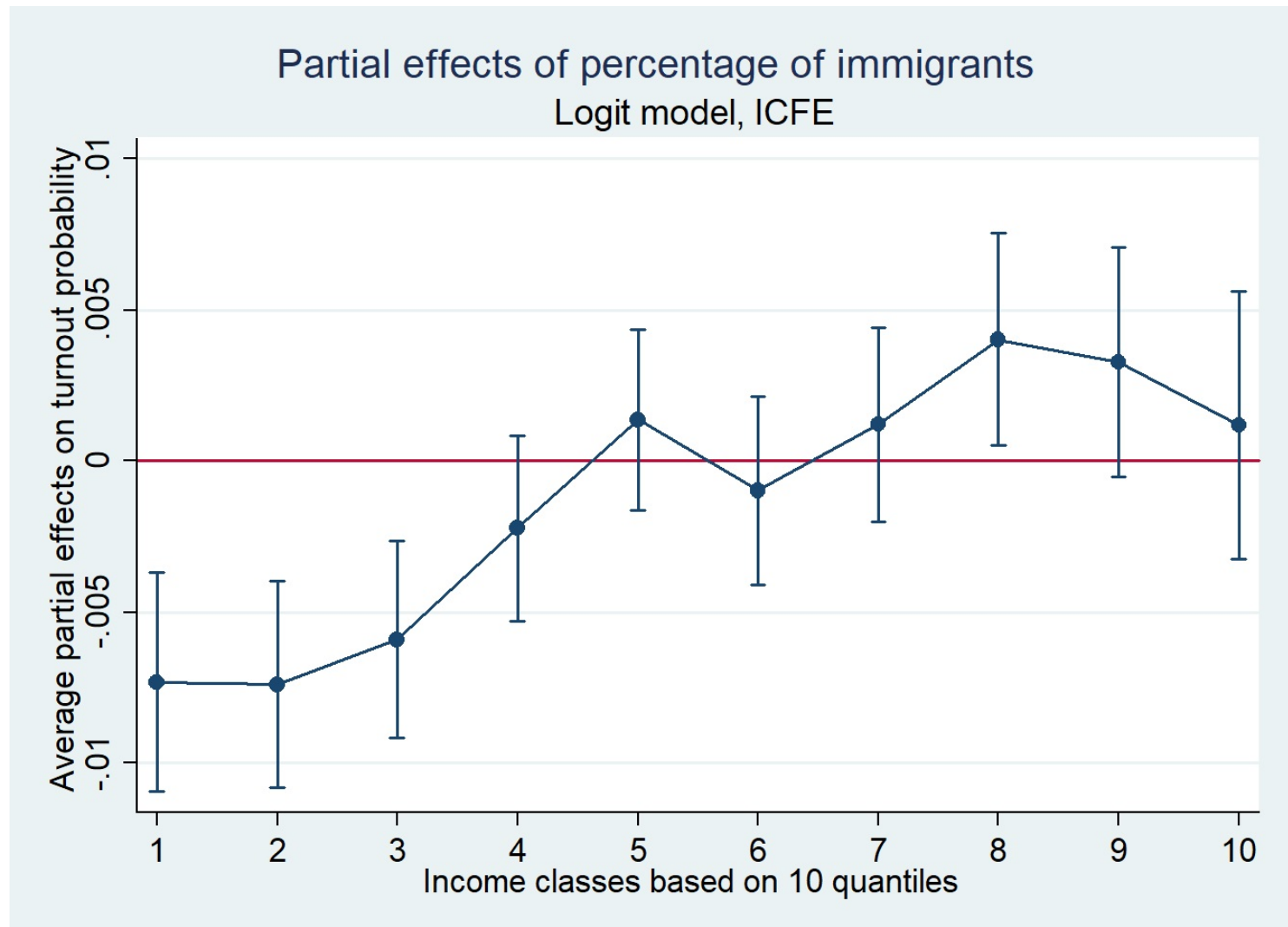

Figure A4 


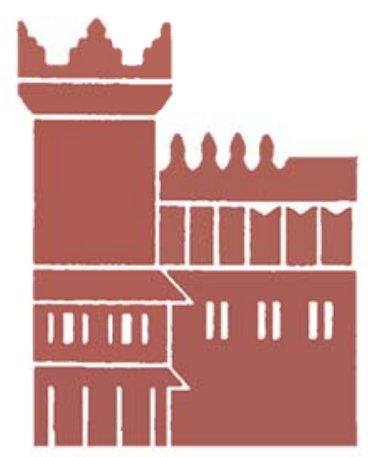

Alma Mater Studiorum - Università di Bologna DEPARTMENT OF ECONOMICS

Strada Maggiore 45

40125 Bologna - Italy

Tel. +39051 2092604

Fax +390512092664

http://www.dse.unibo.it 